A 11103089582

NAT'L INST OF STANDARDS \& TECH R.I.C.

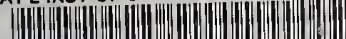

UCE \& TECHNOLOGY:

A11103089582

Gait, Jason/Validating the correctness O

\title{
VALIDATING \\ THE CORRECTNESS OF HARDWARE IMPLEMENTATIONS OF THE NBS DATA ENCRYPTION STANDARD
}

QC

100

.057

$500-20$

1980

C.2
Revised September 1980

NBS Special Publication 500-20

U.S. DEPARTMENT OF COMMERCE National Bureau of Standards 


\section{NATIONAL BUREAU OF STANDARDS}

The National Bureau of Standards' was established by an act of Congress on March 3, 1901. The Bureau's overall goal is to strengthen and advance the Nation's science and technology and facilitate their effective application for public benefit. To this end, the Bureau conducts research and provides: (1) a basis lor the Nation's physical measurement system, (2) scientific and technological services for industry and government, (3) a technical basis for equity in trade, and (4) technical services to promote public safety. The Bureau's technical work is performed by the National Measurement Laboratory, the National Engineering Laboratory, and the Institute for Computer Sciences and Technology.

THE NATIONAL MEASUREMENT LABORATORY provides the national system of physical and chemical and materials measurement; coordinates the system with measurement systems of other nations and furnishes essential services leading to accurate and unitorm physical and chemical measurement throughout the Nation's scientific community, industry, and commerce; conducts materials research leading to improved methods of measurement, standards, and data on the properties of materials needed by industry, commerce, educational institutions, and Government; provides advisory and research services to other Government agencies; develops, produces, and distributes Standard Reference Materials; and provides calibration services. The Laboratory consists of the following centers:

Absolute Physical Quantities ${ }^{2}$ - Radiation Research - Thermodynamics and Molecular Science — Analytical Chemistry - Materials Science.

THE NATIONAL ENGINEERING LABORATORY provides technology and technical services to the public and private sectors to address national needs and to solve national problems; conducts research in engineering and applied science in support of these efforts; builds and maintains competence in the necessary disciplines required to carry out this research and technical service; develops engineering data and measurement capabilities; provides engineering measurement traceability services; develops test methods and proposes engineering standards and code changes; develops and proposes new engineering practices; and develops and improves mechanisms to transfer results of its research to the ultimate user. The Laboratory consists of the following centers:

Applied Mathematics - Electronics and Electrical Engineering ${ }^{2}$ - Mechanical

Engineering and Process Technology ${ }^{2}$ - Building Technology - Fire Research -

Consumer Product Technology _. Field Methods.

THE INSTITUTE FOR COMPUTER SCIENCES AND TECHNOLOGY conducts research and provides scientilic and technical services to aid Federal agencies in the selection, acquisition, application, and use of computer technology to improve effectiveness and economy in Government operations in accordance with Public Law 89-306 (40 U.S.C. 759), relevant Executive Orders, and other directives; carries out this mission by managing the Federal Information Processing Standards Program, developing Federal ADP standards guidelines, and managing Federal participation in ADP voluntary standardization activities; provides scientific and technological advisory services and assistance to Federal agencies; and provides the technical foundation for computer-related policies of the Federal Government. The Institute consists ol the following centers:

Programming Science and Technology - Computer Systems Engineering.

Headquarters and Laboratories at Gaithersburg, MD, unless otherwise noted; mailing address Washington, DC 20234

'Some divisions within the center are located at Boulder, CO 80303. 


\section{COMPUTER SCIENCE \& TECHNOLOGY}

Validating the Correctness

of Hardware Implementations of the

Hatlonal Buroas of Siander

Listary, eni admin. Fiss

NBS Data Encryption Standard

Jason Gait

Center for Programming Science and Technology

Institute for Computer Sciences and Technology

National Bureau of Standards

Washington, D.C. 20234

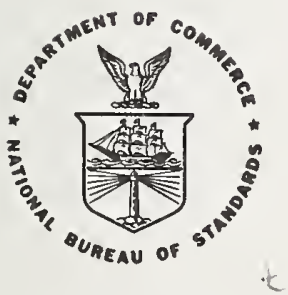

U.S. DEPARTMENT OF COMMERCE, Philip M. Klutznick, Secretary

Luther H. Hodges, Jr., Deputy Secretary

Jordan J. Baruch, Assistant Secretary for Productivity, Technology and Innovation NATIONAL BUREAU OF STANDARDS, Ernest Ambler, Director

Revised September 1980 


\title{
Reports on Computer Science and Technology
}

The National Bureau of Standards has a special responsibility within the Federal Government for computer science and technology activities. The programs of the NBS Institute for Computer Sciences and Technology are designed to provide ADP standards, guidelines, and technical advisory services to improve the effectiveness of computer utilization in the Federal sector, and to perform appropriate research and development efforts as foundation for such activities and programs. This publication series will report these NBS efforts to the Federal computer community as well as to interested specialists in the academic and private sectors. Those wishing to receive notices of publications in this series should complete and return the form at the end of this publication.

\section{National Bureau of Standards Special Publication 500-20}

Nat. Bur. Stand. (U.S.), Spec. Publ. 500-20, 46 pages (Revised Sept. 1980) CODEN: XNBSAV

\author{
Library of Congress Catalog Card Number: 77-16067
}


1. INTRODUCTION $\ldots \ldots \ldots \ldots \ldots \ldots \ldots \ldots \ldots \ldots \ldots \ldots \ldots \ldots \ldots$

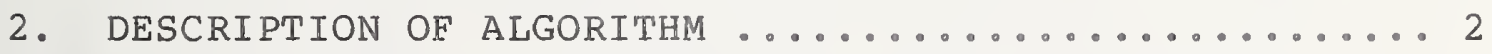

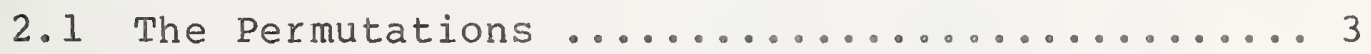

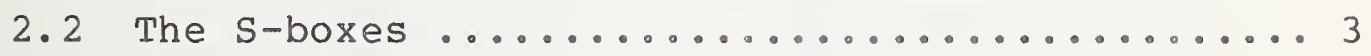

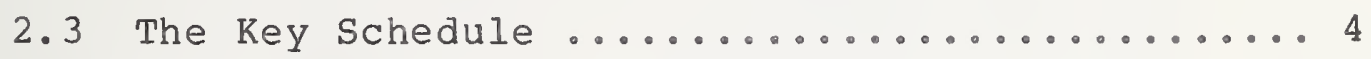

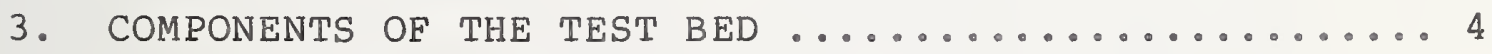

4. THE DEVICE VALIDATION PROCEDURE .............. 13

4.1 The Device/Test-bed Interface ............ 13

4. 2 Validating the Implementation ........... 14

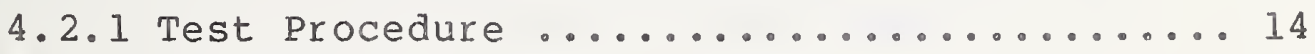

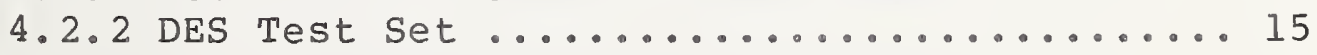

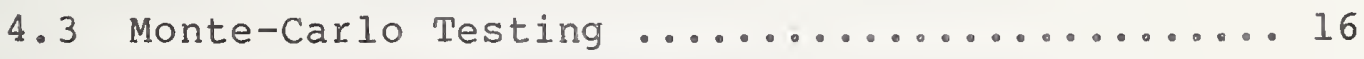

4.4 Procedure for Requesting Validation Service.. 18

5. PREPARATION OF DEVICE VALIDATION REPORT .......... 20

6. Appendix A: The DES Algorithm Specification ....... 22

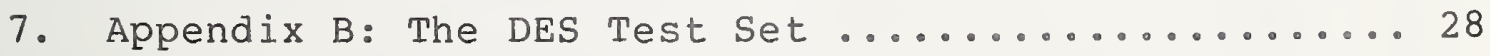

8. Appendix C: Interface Specifications ............ 34 


\section{LIST OF FIGURES}

page

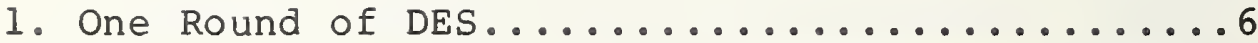

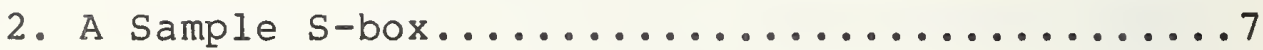

3. The Key Schedule...................

4. Sample Round Outputs....................

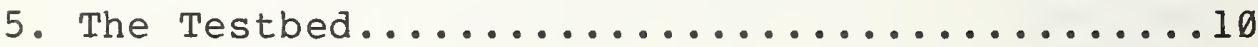

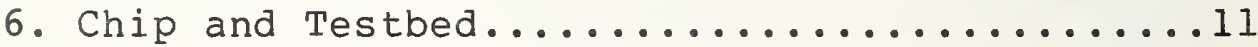

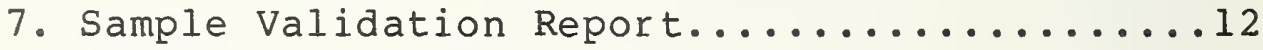

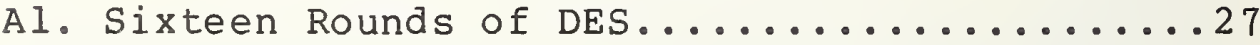

Cl. Interface Line Specifications............36

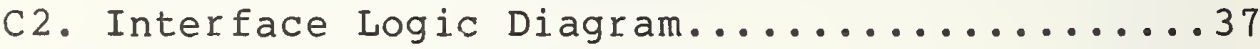

C3. Interface Input Byte Numbering..........38

C4. Interface Output Byte Numbering.........39 
Validating the Correctness of Hardware lmplementations of the NBS Data Encryption Standard

Jason Gait

This publication describes the design and operation of the NBS testbed that is used for the validation of hardware implementations of the Federal Information Processing Data Encryption Standard (DES). A particular implementation is verified if it correctly performs a set of 291 test cases that have been defined to exercise every basic element of the algorithm. As a further check on the correctness of the implementation an extensive Monte-Carlo test is performed. This publication includes the full specification of the DES algorithm, a complete listing of the DES test set and a detailed description of the interface to the testbed.

Key words: security; interface testbed; test cases; validating correctness.

Communications cryptography; requirements; security; encryption Monte-Carlo computer standard; testing;

\section{INTRODUCTION}

The National Bureau of Standards has built a hardware testbed facility to validate manufacturer's implementations of the Federal Information Processing Data Encryption Standard (DES) [3]. The facility includes a hardware implementation of the DES built by NBS in TTL logic and capable of performing an encryption or decryption in 8 micro-seconds. The NBS DES unit is controlled by a microcomputer, which is downstream-loaded with the test program by a time-shared program (currently running on a PDP-11/45**). When a manufacturer submits a DES device for validation, the device is interfaced to a microcomputer in parallel with the NBS DES unit and its correctness is evaluated by comparison with the NBS DES unit. The device and the NBS DES unit are run

* The designations of computer products contained in this report are included for technical accuracy and completeness. The National Bureau of Standards does not endorse the products of any particular computer manufacturer. 
simultaneously and synchronously as the test cases are computed.

Nineteen encryptions and comparisons are required to fully exercise the non-linear substitution tables, or $\mathrm{S}-$ boxes. The key schedule is exercised by presenting 56 basis vectors for both encryption and decryption, an additional 112 tests. The initial and final permutations are tested by presenting to each permutation 64 basis vectors, for 128 more tests during which the expansion operator $\mathrm{E}$ is automatically verified. The permutation $P$ is verified by performing 32 more encryptions. Thus, a total of 235 encryptions and 56 decryptions are used in the DES test set.

At his option, a manufacturer of a DES implementation may provide an interface to the DES testbed when he submits his device for validation, or NBS will construct the interface from a full specification of device characteristics provided by the manufacturer. If the submitter elects to provide his own interface, he should design it in accordance with the specifications given in this document.

\section{DESCRIPTION OF ALGORITHM}

The Federal Information Processing Data Encryption Standard published on January 15, 1977 [3] is a complex non-linear ciphering algorithm that was designed with a view to efficient hardware implementation. Although there have been software implementations, they do not comply with the standard and they are generally quite inefficient compared to hardware versions [6]. The DES algorithm operates on 64 bits of plaintext to produce 64 bits of ciphertext under the action of a 56-bit keying parameter. With the exception of initial and final permutations, the algorithm is a series connection of sixteen rounds, one of which is depicted in figure 1. Each round uses 48 bits of the key in a sequence determined by a key schedule. With the exception of this difference in the round keys, the sixteen rounds are identical to one another. Each round receives an input of 64 bits; the 32-bit right half is expanded by the linear operator E to 48 bits and the result is mod two added to the round key; the 48 bit sum is divided into eight 6-bit blocks, each of which determines a 4-bit s-box entry; the resulting 32 bits are added mod two to the left half and the two halves are interchanged, thus producing 64 bits of output for the round. Sixteen rounds connected in series, each 
using a different round key as determined by the key schedule, together with initial and final permutations make up the DES algorithm. Despite its complexity the DES is capable of operating at high speed when implemented in hardware...for example, an encryption or decryption of one 64-bit block on the NBS DES unit takes 6 micro-seconds. Guidelines on the proper usage of the DES are published in [8].

An example of round-by-round encryption for a given key and plaintext is shown in figure 4. Appendix A contains a complete functional description of the DES algorithm parameters, i.e., permutations, S-boxes and key schedule.

\section{1 The Permutations}

The role of the permutations is to thoroughly mix the data bits so they cannot be traced back through the s-boxes. Most of the permutations have been designed for efficient hardware realization. In particular, the initial and final permutations are byte oriented, and the controlling microcomputer outputs data to the DES hardware eight bits at a time to take advantage of this feature. In addition to performing a permutation, the operator E expands its 32 bit input to a 48 bit output that is added mod 2 to the round key. The permutation $P$ intermixes the bits that result from the S-box substitution in a complex way to prevent bit tracing. The permutations in the key-schedule intermix the key bits among the round keys in such a way as to equalize key-bit utilization...no key bit is used more than 15 times nor less than 12 times.

Each permutation is a linear operator, and so can be thought of as an $n \times m$ matrix and can be completely validated if it operates correctly on an appropriate set of basis vectors. The set of tests for the permutation operators is founded on this principle, and the test cases have been constructed to present a complete set of basis vectors to each operator.

\section{2 The S-boxes}

The non-linear substitution tables, or S-boxes, constitute the most important part of the algorithm. The purpose of the S-boxes is to ensure that the algorithm is not linear, and hence too weak to stand up under cryptanalytic attack $[1,2]$. Each of the eight $S$-boxes, such as is shown in 
figure 2, contains 64 entries, organized as a $4 \times 16$ matrix. Each entry is a four bit binary number, represented as 0-15 in figure 2, so the output of the parallel connection of eight s-boxes is 32 bits. A particular entry in a single S-box is selected by six bits, two of which select a row and four select a column. The entry in the corresponding row and column is the output for that input. Each row in each $\mathrm{S}-\mathrm{box}$ is a permutation of the numbers $0-15$, so no entry is repeated in any one row.

There is no obvious small set of inputs that could be used to verify the S-boxes, so an extensive series of Monte-Carlo experiments was performed to discover a relatively small set of inputs that would exercise every $\mathrm{S}$-box entry at least once. Nearly 200 separate trials were made, and among these were several test sets of 19 inputs which exercised every $S-b o x$ entry. One of these sets is used as the DES test set for the $S$-boxes.

2.3 The Key Schedule

The purpose of the key schedule is to provide a thorough intermixing of the key bits for each round. Figure 3 shows how the key schedule determines the sixteen 48-bit round keys from the 56-bit encryption key. The key schedule is linear, so its implementation can be verified by presenting 56 basis vectors as keys, encrypting known input and comparing with known output. The encryption process depends on left shifts in the key schedule, but decryption depends on right shifts, so an additional 56 decryptions are required to test this. The key schedule is extremely important to the security of the algorithm: it has been shown [4] that similar algorithms without key schedules are substantially weaker, even if they have much larger keys.

\section{COMPONENTS OF THE TEST BED}

The data encryption testbed has been established within the Institute for Computer Sciences and Technology at the National Bureau of Standards. In order to provide a validation service for DES implementations, the testbed was 
conceived and developed as a joint effort of ICST: s Center for Programming Science and Technology and the center for Computer Systems Engineering.

The data encryption testbed was developed in three phases. During phase one the DES algorithm was implemented in readily available TTL hardware technology. Two units are presently in operation. Phase two incorporated these units in a communication channel between a high speed computer terminal and the ICST Computer Facility. A microcomputer is used to interface the NBS DES unit to the data communications channel, as in figure 5. Phase three provided a method of validating commercial data encryption devices implementing the DES.

The most important component of the testbed is the DES algorithm implemented in standard TTL logic. This device performs an encryption or decryption in eignt micro-seconds, and takes 26 micro-seconds to load key or plaintext or to unload ciphertext. This is in contrast to execution times on the order of 30-100 milli-seconds for known software implementations. Figure 6 shows the DES testbed set up for the validation of a manufacturer's DES device. The testbed uses a microcomputer, the NBS DES unit, the proprietary DES device and its interface to the microcomputer port, an operator's terminal (CRT) and a connection to the NBS computer ( PDP-11/45). The latter operates in time-sharing mode using the UNIX operating system. The microcomputer contains a small monitor program in read-only memory that is used to permit downstream-loading of the validation software and test data from ( PDP-11/45) files under control of the operator's terminal. The current version of the validation software was written and compiled on the PDP-11/45 using an in-house cross-assembler. 
$L_{n}$

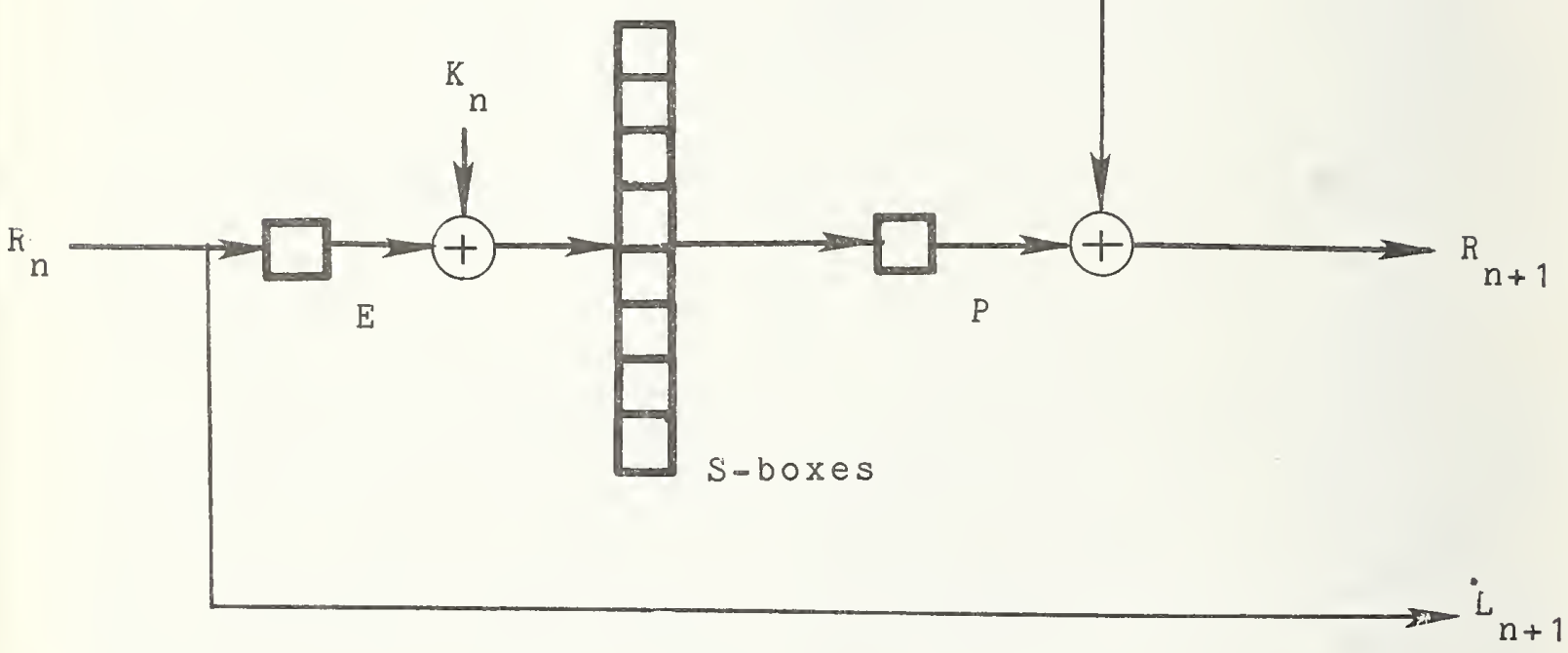

Figure 1 . One of sixteen rounds of the DES. The sixteen rounds are connected in series and have an initial and

final permutation. A key schedule determines the round keys 
Figure 2: One of the eight S-boxes in the DES. An S-box entry is determined by a six bit input, four of which determine a column and two determine a row. The output is the four bit S-box entry specified by the row and column. The eight s-boxes are connected in parallel, and are used in each of the sixteen rounds of the DES.

$\begin{array}{llllllllllllllll}14 & 4 & 13 & 1 & 2 & 15 & 11 & 8 & 3 & 10 & 6 & 12 & 5 & 9 & 0 & 7\end{array}$

$\begin{array}{lllllllllllllllll}\emptyset & 15 & 7 & 4 & 14 & 2 & 13 & 1 & 10 & 6 & 12 & 11 & 9 & 5 & 3 & 8\end{array}$

$\begin{array}{lllllllllllllllll}4 & 1 & 14 & 8 & 13 & 6 & 2 & 11 & 15 & 12 & 9 & 7 & 3 & 10 & 5 & 0\end{array}$

$\begin{array}{llllllllllllllll}15 & 12 & 8 & 2 & 4 & 9 & 1 & 7 & 5 & 11 & 3 & 14 & 10 & 0 & 6 & 13\end{array}$ 
left shift

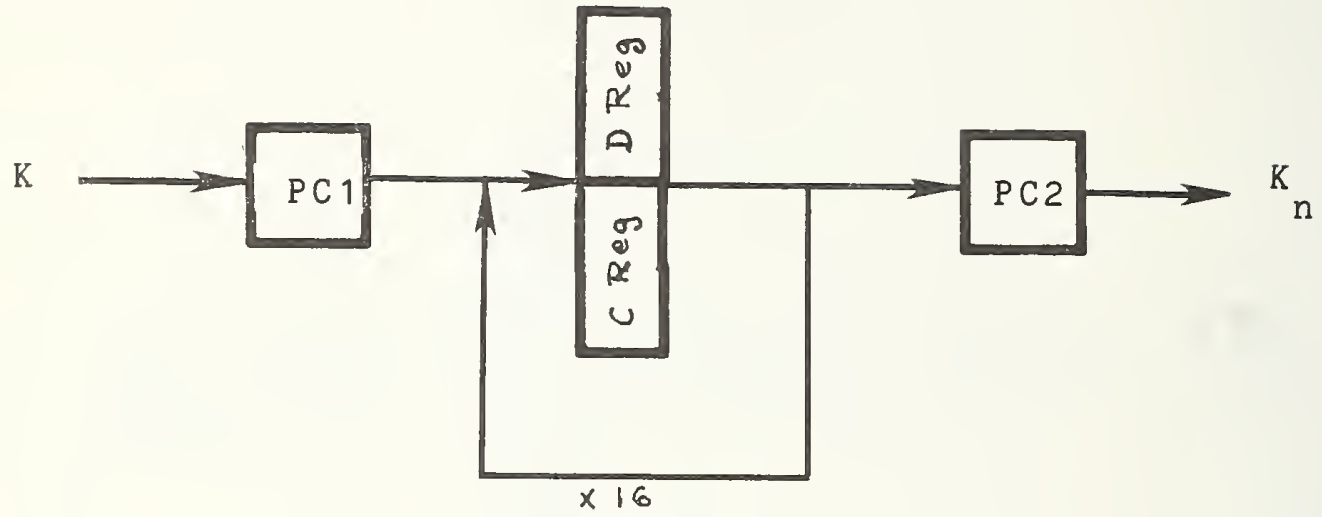

Figure 3 . The key schedule for the DES. The operator PC 1 strips away the parity bits from the 64-bit key to produce the 56-bit active key. This is split into two 28 bit registors which are rotated by one or two bits during each round.The operator PC2 produces the 48-bit round key after the bits have been permuted in the registers. 
Figure 4: Sample round outpits for the DES. For this example the key is $10316 \mathrm{E} 028 \mathrm{C} 8 \mathrm{~F} 3 \mathrm{~B} 4 \mathrm{~A}$ and the plaintext is $\emptyset \emptyset \emptyset \emptyset \emptyset \emptyset \emptyset \emptyset \emptyset \emptyset \emptyset \emptyset \emptyset \emptyset \emptyset \emptyset$.

$\mathrm{L}$
$0 \emptyset \emptyset \emptyset \emptyset \emptyset \emptyset \emptyset$
$47092 \mathrm{~B} 5 \mathrm{~B}$
$53 \mathrm{~F} 372 \mathrm{AF}$
$9 \mathrm{~F} 1 \mathrm{D} 158 \mathrm{~B}$
$8109 \mathrm{CBEE}$
60448698
$29 \mathrm{EBB} 1 \mathrm{~A} 4$
$620 C \mathrm{C} 3 \mathrm{~A} 3$
DEEB 3D 8A
A $1 A 0354 D$
9F冋303DC
FD898EE8
2D IAEIDD
CBC 829FA
B 367DEC 9
3F 6C 3EFD

$\mathrm{R}$

$47092 \mathrm{~B} 5 \mathrm{~B}$

53F $372 \mathrm{AF}$

$9 \mathrm{~F} 1 \mathrm{D} 158 \mathrm{~B}$

$81 \emptyset 9 \mathrm{CBEE}$

60448698

29 EBB IA 4

$62 B C C 3 A 3$

DEEB 3D 8A

$A \perp A \emptyset 354 D$

$9 \mathrm{~F} \emptyset 3 \emptyset 3 \mathrm{DC}$

FD898EE 8

2D IAEIDD

CBC 829FA

B 367DEC 9

3F 6 C $3 E F D$

$5 A 1 E 5228$

OUTPUT

82DCBAFBDEAB 6602 


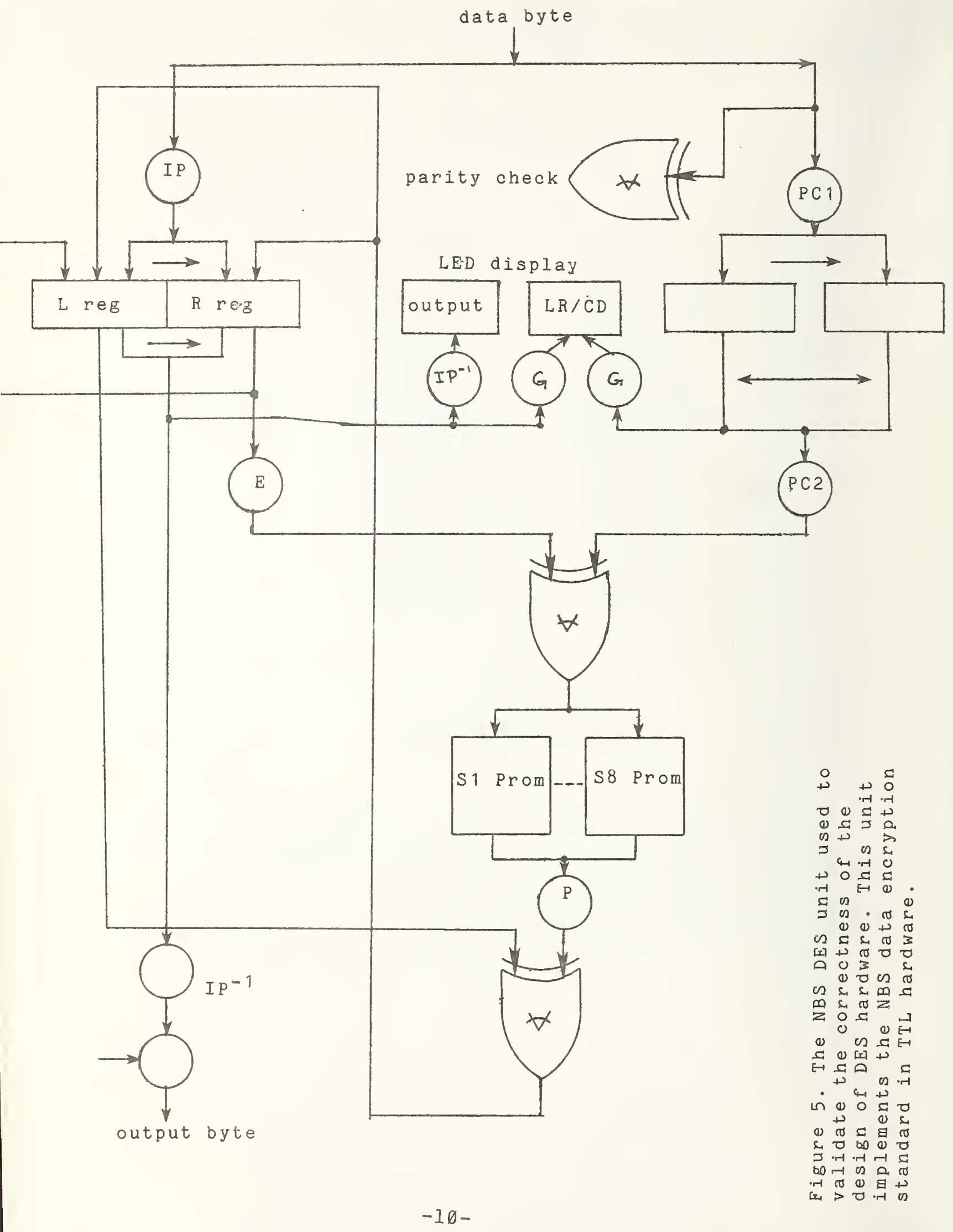


Microcomputer Prolog 8080

serial

I/O port

DES

port

serial

I/O port

NBS

DES

Unit

port
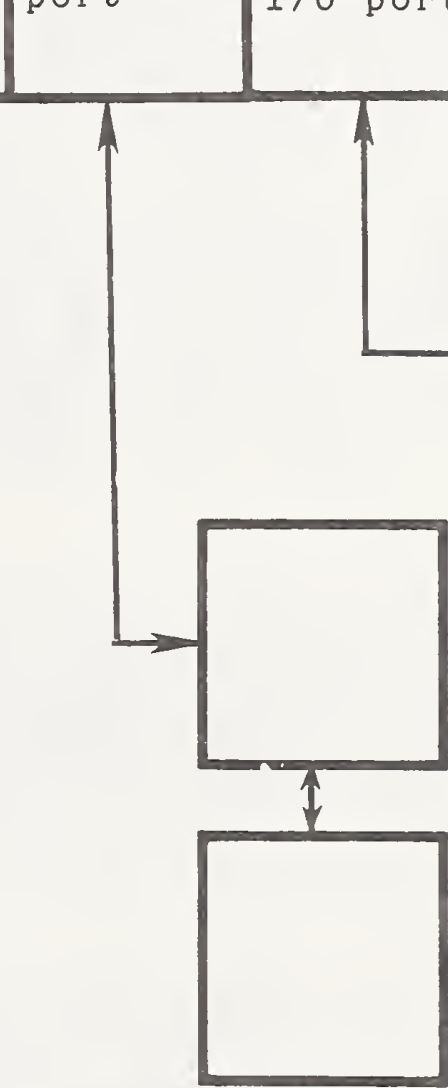

interface to commercial

DES device

Commercial

DES device

Figure 6 . Current architecture of the validation testbed. The interface can be provided to NBS with the hardware, or it can be built by NBS at cost from specifications of the proprietary hardware. 
Figure 7: Sample validation certificate. This certificate is provided by NBS for encryption hardware implementing the DES that has been tasted successfully. A prospective vendor of DES encryption equipment to Federal agencies must obtain a certificate of validation.

\section{VALIDATION CERTIFICATE}

The National Bureau of Standards has tested an encryption device, identified as............ manufactured by............. in accordance with the specifications of the Data Encryption Standard (FIPS Pub 46) and in accordance with the procedures specified in NBS Special Publication $500-20$.

The device has passed the DES test set, and in addition has passed a Monte Carlo test that lasted four million iterations. For the Monte Carlo test the initial value of the key was........................... and the initial value of the input was................. The final value of the key was ........... and the final value of the output was

Devices bearing the same identification and manufactured to the same design specifications may be labeled as complying with the standard. No reliability test has been performed and no warranty of the devices by the National Bureau of Standards is either expressed or implied.

Dated..............

signed.............

(Director, Center for Programming Science and Technology

Institute for Computer Sciences and

Technology, National Bureau of

Standards) 
The device validation procedure verifies that the manufacturer's hardware design of the DES correctly performs the algorithm. To do this a manufacturer submits a single device from his production line for testing. The validation procedure confirms that the device submitted correctly performs the DES algorithm. Quality control of devices from the production line is the responsibility of the manufacturer. NBS does not certify the reliability of DES devices, only the correctness of the way they implement the DES.

An interface can be provided by NBS for the device submitted or the manufacturer can provide his own interface. The device runs under microcomputer control while performing the encryptions and decryptions of the DES test set, the results being compared to known results in the microcomputer. This test takes less than five minutes. The Monte Carlo test is performed by the commercial device and the NBS device in parallel. This test may run as long as eight hours. The successful completion of the tests will result in the issuance of a validation certificate for the manufacturer's implementation of the DES, and Federal agencies may then purchase identical devices from the manufacturer which are in conformity with the standard.

\subsection{The Device/Test-bed Interface}

An interface must be designed specifically for each proprietary implementation submitted for validation. This is the most time consuming aspect of the testbed procedure and the manufacturer is required to submit detailed characteristics of his device with regard to voltage levels and operating requirements to facilitate this phase.

The NBS microcomputer interface is designed for use with the NBS DES unit, which uses TTL MSI logic. Firms with commercial implementations of the algorithm that are to be validated by NBS may, at their option, have NBS design and build the necessary interface logic and make necessary software changes to the microcomputer program or they may design their own interface logic that will make their device appear to be identical to the NBS device.

In the former case, it will be necessary to supply adequate documentation to NBS on the operation of the commercial device so that NBS can design the necessary interface logic and software modifications. This documentation should 
include a definition of all I/O leads, their pin numbers and a narrative description of the operation of the device and of the particular signals needed to operate it. Signal specifications should include the technology to be used by the external circuits (TTL, CMOS, etc.), any external puliup resistors required, fan out limitations and any unique voltage levels. All power supply voltages needed should be specified. If any of this information is proprietary, this should be so noted.

Full details of the interfacing requirements are included as Appendix C.

\subsection{Validating the Implementation}

The testbed verifies the correctness of an implementation by performing a series of tests on the device submitted. The tests are chosen to present basis vectors to each of the matrix operators in the algorithm and to exercise every element in each S-box.

4. 2.1 Test Procedure. The NBS standard test consists of 291 individual sets of key, plaintext, and ciphertext. The data are stored in a (PDP-II/45) file with each line in the file containing one individual test, e. g.,

\section{Kø101010101010101 P13213AB764588787 S8000000000000000.}

The source text of the test program currently resides on a PDP-11/45, and must first be cross-assembled for the PROLOG microcomputer. The resulting object module is downstream loaded into the PROLOG microcomputer via an RS-232 interface. The down- stream loading occurs using a special, almost transparent IO handler on the PROLOG which reads a character from one port (the terminal) and passes it through to the other port $(\mathrm{PDP}-11 / 45)$ and vice versa.

Currently, a program on the PDP-1l/45 is executed which starts a process on the PROLOG by sending a special character that starts execution of the test program. The $(P D P-11 / 45)$ process sends the PROLOG the test data one line at a time. The data is sent in hexadecimal ASCII format. Each line is separated into three sections by tabs and special control characters appear at the beginning of each of these sections. A ' $K$ ' at the beginning of the first column indicates that the following 16 characters represent the key. The control character in the second column indicates which operation is to be performed, a ' $\mathrm{P}$ ' for encryption and a 'S' for decryption. The control character in the third column is the complement of that in the second, indicating 
that the data following is plaintext or ciphertext.

Once the data has been received, the microcomputer program then loads the test device with the key, followed by the data, and initiates the test. It receives the encrypted or decrypted data back from the test device, and compares it with the expected result. Any deviation in the comparison results in an error message being printed at the console, indicating which individual. test failed. The rest of the test is continued. The normal execution time of this test is 3-5 minutes, but it is mainly dependent on the transfer time of the test data, which is transmitted to the PROLOG microcomputer at 2400 bits per second.

4.2.2 DES Test Set. The tests have been constructed to validate each of the following components of the algorithm:

1. Initial permutation, IP

2. Inverse permutation, IP-1

3. Expansion matrix, E

4. Data Permutation, P

5. Key Permutation, PC1

6. Key Permutation, PC2

7. Substitution tables: $\mathrm{S}_{1}, \mathrm{~S}_{2}, \ldots, \mathrm{s}_{8}$

TEST 1: Set Key=ø and encrypt the 64-bit data vectors $e^{i}: \quad i=1, \ldots, 64 ;$ a set of basis vectors.

Basis vectors have all zeros except for a single 1 in the ith position. Compare the resulting cipher $c^{i}$ with the known results.

CONCLUSIONS: Correct operation verifies the initial permutation, IP. As a full set of basis vectors is also presented to the expansion matrix, $\mathrm{E}$, this operation is also verified.

TEST 2: Set Key=ø and encrypt the results $c^{i}$ obtained in TEST 1 .

CONCLUSIONS: As the set of basis vectors are recovered, each $e^{i}$ is presented to the inverse permutation, IP-1, thus verifying it.

TEST 3: To test the permutation operator $P$, set the plaintext to zero and process the 32 keys in PTEST. This presents a complete set of basis vectors to $P$.

TEST 4: part 1: Set Data=ø and use the keys $e^{i}: \quad i=1, \ldots, 64$ ignoring $i=8,16, \ldots, 64$. 
Since the 56 possible basis vectors which yield unique keys are used, this is a complete set of basis vectors for PCl. Compare the results to the known values.

CONCLUSIONS: The key permutation, PCl, is verified. Since the key schedule consists of left shifts, as i. ranges over the index set, a complete set of basis vectors is also presented to PC2, so this is verified.

Part 2: set data $=c^{i}$ from part 1 and use the keys $e^{i}$ : $i=1, \ldots, 64$ ignoring $i=8,16, \ldots 64 . \quad$ Then decipher. This tests the right shifts in the key schedule during deciphering.

TEST 5: Set Data and Key equal to the inputs defined in the Substitution Table test. These are a set of 19 key-data pairs that result in every entry of all eight substitution tables being used at least once. Compare the results to the known values.

CONCLUSIONS: The eight substitution tables of 64 entries each are verified.

Appendix B contains a listing of the complete set of standard tests described above.

4.3 Monte-Carlo Testing

Since the test set is known to all, an additional series of tests is performed using pseudo-random data to verify that the device has not been designed just to pass the test set. In addition a successful series of Monte Carlo tests give some assurance that an anomalous combination of inputs does not exist that would cause the device to hang or otherwise malfunction for reasons not directly due to the implementation of the algorithm. While the purpose of the DES test set is to insure that the commercial device performs the DES algorithm accurately, the Monte Carlo test is needed to provide assurance that the commercial device was not built expressly to satisfy the announced tests. 
Each device that is submitted for testing is subjected to a Monte-Carlo test on pseudo-random data that will run for a fixed number of iterations for all proprietary devices submitted. An additional purpose of this test is to verify that no undesirable condition within the device will cause the key or plaintext to be exposed in place of ciphertext due to a design error. The Monte-Carlo test is not a reliability test but merely checks for the presence of an apparent operational error. The pseudo-random data is initialized by the test operator at the console, and the test is terminated after a predetermined number of iterations unless there is a failure, in which case the data causing the failure is displayed at the console. The pseudo-random inputs required for the test are produced by the DES itself, used as a pseudo-random number generator. It was shown in [5] that the DES is a statistically good pseudo-random number generator, and the likelihood of cycling is very low during observable time periods.

The Monte-Carlo test, unlike the DES test, runs only on the PROLOG microcomputer. However, the source program is currently kept on a PDP-11/45 and must be cross-assembled and downstream loaded to the PROLOG. Once the program has been loaded, its execution begins immediately. Dialogue consists of prompting the operator for the initial key and seed (plaintext). These are entered as 16 hexadecimal characters. Once this initialization is complete the test begins.

The Monte-Carlo test consists of eight million encryptions and four million decryptions, with one decryption and two encryptions making up a single test. Each of the four miliion tests is run on both the test device and the NBS DES unit, with comparisons being made after each operation. Each individual test consists of enciphering the plaintext on both the NBS and test devices, comparing the results, enciphering the ciphertext on both the NBS and test device, comparing these results, then deciphering the output of the second encryption on the test device, and comparing this with the first ciphertext. The key remains the same, while the output of the second encryption becomes the new plaintext, as this process is repeated 10,000 times. At this time a new key is generated from the output of the first encryption that occurred in the 10,000th iteration of the preceding group of tests. A message is printed out at the console indicating that the nth group of 10,000 iterations has been completed. This series runs until completion, or until an error is detected. If an error is detected, the current key, the plaintext, the result from the NBS device and the result from the test device is printed out at the console. The error message states whether the error was in 
the first encryption, the second encryption or the decryption.

This test is allowed to run until four million complete tests, comprising 8 million encipherments and 4 million decipherments, have been generated on the test device. Each group of 10,000 iterations takes approximately one minute to complete, but there will be variations from one proprietary device to another.

4.4 Procedure for Requesting Validation

Service

The general policy for validation test procedures is specified in Part 200 of title 15, Code of Federal Regulations, and in the publication "Calibration and Test Services of the National Bureau of Standards" (NBS Special Pub. 250 [7]). Procedures for formally requesting validation services, shipping, testing and preparation and use of the validation certificate are included. Specific instructions for a manufacturer desiring a formal DES validation are pro-. vided below.

A formal request for a validation should be sent prior to the time a device is shipped to NBS. This should provide clear identification of the device being submitted, identification of the individual acting as technical representative for the test ( $i$. e., name, address and telephone no.) and instructions for the return of the device. The formal request should also contain authorization to operate the device and authorization to charge for the test. The name and address of the individual to whom the bill should be sent should also be included.

The request for validation, complete specifications of the device to be tested (sufficient for interfacing the device to the DES testbed) and the device itself should be sent to:

Director, Center for Programming Science and Technology Institute for Computer Sciences and Technology A-247 Technology Building National Bureau of Standards Washington, D. C., 20234 
The three items should be sent under separate cover. Inquiries regarding the test should be similarly addressed(or tel. 301-921-3531). The request and specifications should be sent first and the device shipped only after NBS has responded with an estimated cost of validation and a tentative testing schedule.

Insofar as possible, NBS personnel will work jointly with the manufacturer's technical representative in performing a timely test. Special provisions for testing devices that have been integrated into larger electronics equipment will be made as appropriate. Validation of DES devices only assures that the devices correctly implement the DES. The validation procedures do not include reliability testing.

Any device shipped to NBS should be sent in a reuseable container packed to minimize the potential for damage in transit. Shipping and insurance costs must be paid by the manufacturer. NBS will assume no responsibility for damage during shipment, handing or in testing.

A validation certificate will be issued to the manufacturer when the tests are successfully completed. Notification will be made to the technical representative if the tests for any reason cannot be carried out. The tests may be terminated at the request of the manufacturer at any time prior to completion and a bill for costs will be issued.

NBS does not approve, recommend or endorse any commercial product. NBS in no way guarantees that devices similar to the device validated can or will pass the validation tests. However, a manufacturer may certify that devices identical to and bearing the same identification as the device validated implement the DES. Such a claim will make the devices eligible for procurement and use by government agencies. However, no expressed or implied agreement for such procurement is made by NBS.

In accordance with Federal law ( 15 United States Code 275a), fees are charged for all measurement services performed by the National Bureau of Standards. Fees will include the cost of labor and materials used in performing the validation tests and in issuing a validation certificate. Labor costs will include administrative, engineering and programming personnel participating in the test. Labor rates will be determined by the cost of the personnel, including applicable overhead. Materials cost will be actual cost to NBS. Travel costs, when necessary, will be actual costs to NBS. Bills will be issued upon completion or termination of the test. A validation certificate will be issued upon 
receipt of payment.

\section{PREPARATION OF DEVICE VALIDATION REPORT}

Each manufacturer who submits an implementation for validation will receive a validation certificate detailing the results of the standard test and of the Monte-Carlo test. The successful performance of the tests and the submission of a properly completed validation certificate on the part of the manufacturer is required by the Federal Government in all cases where procurement is being considered by a Federal agency or department. A typical validation certificate will state that the device submitted by the manufacturer satisfied the DES test set, and will also give the starting parameters and final results for the MonteCarlo test, so the test can be exactly repeated in the future should any question arise. A sample validation certificate is shown in figure 7 .

\section{ACKNOWLEDGEMENTS}

Dana "Grubb and Lou Palombo, of the Center for Computer Systems Engineering, designed and constructed the NBS DES unit. Joe Sokol, of the Center for Programing Science and Technology, was responsible for the production of the testbed scftware. William Truitt, of the Center for Computer Systems Engineering, adapted and interfaced the microcomputer for the testbed.

Dennis Branstad, of the Center for Programming Science and Technology, was responsible for the conception and overall design of the DES testbed. Seymour Jeffery, Director of the Center for Programming Science and Technology, has provided consistent support for the project since its incepticn.

Thomas N. Fyke, Jr., Director of the Center for Computer Systems Engineering, provided guidance on the design of the validation certificate. Gordon Fields, staff Attorney in the NBS Legal Office, provided many suggestions. 


\section{APPENDICES}

$-21-$ 


\section{Appendix A: The DES Algorithm Specification}

For the convenience of the reader, this appendix contains a complete specification of the parameters involved in the definition of the DES algorithm.

The DES acts on a 64 bit block of plaintext, which is first permuted by IP:

$\begin{array}{llllllll}58 & 50 & 42 & 34 & 26 & 18 & 10 & 2\end{array}$

$\begin{array}{llllllll}60 & 52 & 44 & 36 & 28 & 20 & 12 & 4\end{array}$

$\begin{array}{llllllll}62 & 54 & 46 & 38 & 30 & 22 & 14 & 6\end{array}$

$\begin{array}{llllllll}64 & 56 & 48 & 40 & 32 & 24 & 16 & 8\end{array}$

$\begin{array}{llllllll}57 & 49 & 41 & 33 & 25 & 17 & 9 & 1\end{array}$

$\begin{array}{lllllllll}59 & 51 & 4 & 3 & 35 & 27 & 19 & 11 & 3\end{array}$

$\begin{array}{llllllll}61 & 53 & 45 & 37 & 29 & 21 & 13 & 5\end{array}$

$\begin{array}{llllllll}63 & 55 & 47 & 39 & 31 & 23 & 15 & 7\end{array}$

(e. g., bit one of the output is bit 58 of the input and bit two is bit $5 \emptyset$, etc.)

The result is separated into two 32 bit registers, $L$ and $R$, and then passed through the sixteen rounds as in figure Al. The final 64 bit result is operated on by the inverse of IP, IP-1:

$$
\text { I } \mathrm{P}^{-1}
$$

$\begin{array}{llllllll}40 & 8 & 48 & 16 & 56 & 24 & 64 & 32\end{array}$

$\begin{array}{llllllll}39 & 7 & 47 & 15 & 55 & 23 & 63 & 31\end{array}$

$\begin{array}{llllllll}38 & 6 & 46 & 14 & 54 & 22 & 62 & 30\end{array}$

$\begin{array}{llllllll}37 & 5 & 45 & 13 & 53 & 21 & 61 & 29\end{array}$

$\begin{array}{llllllll}36 & 4 & 44 & 12 & 52 & 20 & 60 & 28\end{array}$

$\begin{array}{llllllll}35 & 3 & 43 & 11 & 51 & 19 & 59 & 27\end{array}$

$\begin{array}{llllllll}34 & 2 & 42 & 10 & 50 & 18 & 58 & 26\end{array}$

$\begin{array}{llllllll}33 & 1 & 41 & 9 & 49 & 17 & 57 & 25\end{array}$ 
The round keys $k$ are determined by the key schedule that is diagrammed in figure 3. There are three parameters to be specified, PCl, PC2 and the shift schedule:

PCl

$\begin{array}{lllllll}57 & 49 & 41 & 33 & 25 & 17 & 9\end{array}$

$\begin{array}{lllllll}1 & 58 & 50 & 42 & 34 & 26 & 18\end{array}$

$\begin{array}{lllllll}10 & 2 & 59 & 51 & 43 & 35 & 27\end{array}$

$\begin{array}{lllllll}19 & 11 & 3 & 60 & 52 & 44 & 36\end{array}$

$\begin{array}{llllllll}63 & 55 & 4 & 7 & 39 & 31 & 23 & 15\end{array}$

$\begin{array}{lllllll}7 & 62 & 54 & 46 & 38 & 30 & 22\end{array}$

$\begin{array}{llllllll}14 & 6 & 61 & 53 & 45 & 37 & 29\end{array}$

$\begin{array}{lllllll}21 & 13 & 5 & 28 & 20 & 12 & 4\end{array}$

PC 2

$\begin{array}{llllll}14 & 17 & 11 & 24 & 1 & 5\end{array}$

$\begin{array}{llllll}3 & 28 & 15 & 6 & 21 & 10\end{array}$

$\begin{array}{llllll}23 & 19 & 12 & 4 & 26 & 8\end{array}$

$\begin{array}{llllll}16 & 7 & 27 & 2 \emptyset & 13 & 2\end{array}$

$\begin{array}{llllll}41 & 52 & 31 & 37 & 47 & 55\end{array}$

$\begin{array}{llllll}30 & 40 & 51 & 45 & 33 & 48\end{array}$

$\begin{array}{llllll}44 & 49 & 39 & 56 & 34 & 53\end{array}$

$\begin{array}{llllll}46 & 42 & 50 & 36 & 29 & 32\end{array}$

and the shift schedule is:

Iteration Number of shifts

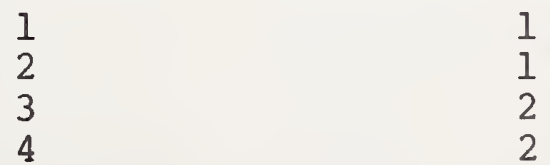


For a single round the expansion operator $E$ and the permutation $P$ need to be specified:

$\begin{array}{rrrrrr}32 & 1 & 2 & 3 & 4 & 5 \\ 4 & 5 & 6 & 7 & 8 & 9 \\ 8 & 9 & 10 & 11 & 12 & 13 \\ 12 & 13 & 14 & 15 & 16 & 17 \\ 16 & 17 & 18 & 19 & 20 & 21 \\ 20 & 21 & 22 & 23 & 24 & 25 \\ 24 & 25 & 26 & 27 & 28 & 29 \\ 28 & 29 & 30 & 31 & 32 & 1\end{array}$

P

$\begin{array}{llll}16 & 7 & 20 & 21\end{array}$

$\begin{array}{llll}29 & 12 & 28 & 17\end{array}$

$\begin{array}{llll}1 & 15 & 23 & 26\end{array}$

$\begin{array}{llll}5 & 18 & 31 & 10\end{array}$

$\begin{array}{llll}2 & 8 & 24 & 14\end{array}$

$\begin{array}{llll}32 & 27 & 3 & 9\end{array}$

$\begin{array}{llll}19 & 13 & 30 & 6\end{array}$

$\begin{array}{llll}22 & 11 & 4 & 25\end{array}$

There remain only the S-boxes: 
$\left(\mathrm{S}_{1}\right.$ is figure 2.)

$$
\mathrm{S}_{2}
$$

$\begin{array}{rrrrrrrrrrrrrrrr}15 & 1 & 8 & 14 & 6 & 11 & 3 & 4 & 9 & 7 & 2 & 13 & 12 & 0 & 5 & 10 \\ 3 & 13 & 4 & 7 & 15 & 2 & 8 & 14 & 12 & 0 & 1 & 10 & 6 & 9 & 11 & 5\end{array}$ $\begin{array}{llllllllllllllll}0 & 14 & 7 & 11 & 10 & 4 & 13 & 1 & 5 & 8 & 12 & 6 & 9 & 3 & 2 & 15\end{array}$ $\begin{array}{llllllllllllllll}13 & 8 & 10 & 1 & 3 & 15 & 4 & 2 & 11 & 6 & 7 & 12 & 0 & 5 & 14 & 9\end{array}$

$\mathrm{s}_{3}$

$\begin{array}{lllllllllllllllll}10 & 0 & 9 & 14 & 6 & 3 & 15 & 5 & 1 & 13 & 12 & 7 & 11 & 4 & 2 & 8\end{array}$ $\begin{array}{llllllllllllllll}13 & 7 & 0 & 9 & 3 & 4 & 6 & 10 & 2 & 8 & 5 & 14 & 12 & 11 & 15 & 1\end{array}$ $\begin{array}{llllllllllllllll}13 & 6 & 4 & 9 & 8 & 15 & 3 & 0 & 11 & 1 & 2 & 12 & 5 & 10 & 14 & 7\end{array}$ $\begin{array}{llllllllllllllll}1 & 10 & 13 & 0 & 6 & 9 & 8 & 7 & 4 & 15 & 14 & 3 & 11 & 5 & 2 & 12\end{array}$

$\mathrm{S}_{4}$

$\begin{array}{llllllllllllllll}7 & 13 & 14 & 3 & 0 & 6 & 9 & 10 & 1 & 2 & 8 & 5 & 11 & 12 & 4 & 15\end{array}$ $\begin{array}{llllllllllllllll}13 & 8 & 11 & 5 & 6 & 15 & 0 & 3 & 4 & 7 & 2 & 12 & 1 & 10 & 14 & 9\end{array}$ $\begin{array}{llllllllllllllll}10 & 6 & 9 & 0 & 12 & 11 & 7 & 13 & 15 & 1 & 3 & 14 & 5 & 2 & 8 & 4\end{array}$ $\begin{array}{llllllllllllllll}3 & 15 & \emptyset & 6 & 10 & 1 & 13 & 8 & 9 & 4 & 5 & 11 & 12 & 7 & 2 & 14\end{array}$

$\mathrm{S}_{5}$

$\begin{array}{llllllllllllllll}2 & 12 & 4 & 1 & 7 & 10 & 11 & 6 & 8 & 5 & 3 & 15 & 13 & 0 & 14 & 9\end{array}$ $\begin{array}{lllllllllllllllll}14 & 11 & 2 & 12 & 4 & 7 & 13 & 1 & 5 & 0 & 15 & 10 & 3 & 9 & 8 & 6\end{array}$ $\begin{array}{llllllllllllllll}4 & 2 & 1 & 11 & 10 & 13 & 7 & 8 & 15 & 9 & 12 & 5 & 6 & 3 & 0 & 14\end{array}$ $\begin{array}{llllllllllllllll}11 & 8 & 12 & 7 & 1 & 14 & 2 & 13 & 6 & 15 & 0 & 9 & 10 & 4 & 5 & 3\end{array}$

$\begin{array}{llllllllllllllll}12 & 1 & 10 & 15 & 9 & 2 & 6 & 8 & 0 & 13 & 3 & 4 & 14 & 7 & 5 & 11\end{array}$ $-25-$ 


$\begin{array}{rrrrrrrrrrrrrrrr}10 & 15 & 4 & 2 & 7 & 12 & 9 & 5 & 6 & 1 & 13 & 14 & 0 & 11 & 3 & 8 \\ 9 & 14 & 15 & 5 & 2 & 8 & 12 & 3 & 7 & 0 & 4 & 10 & 1 & 13 & 11 & 6 \\ 4 & 3 & 2 & 12 & 9 & 5 & 15 & 10 & 11 & 14 & 1 & 7 & 6 & 0 & 8 & 13\end{array}$

$\mathrm{S}_{7}$

$\begin{array}{rrrrrrrrrrrrrrrr}4 & 11 & 2 & 14 & 15 & 0 & 8 & 13 & 3 & 12 & 9 & 7 & 5 & 10 & 6 & 1 \\ 13 & 0 & 11 & 7 & 4 & 9 & 1 & 10 & 14 & 3 & 5 & 12 & 2 & 15 & 8 & 6 \\ 1 & 4 & 11 & 13 & 12 & 3 & 7 & 14 & 10 & 15 & 6 & 8 & 0 & 5 & 9 & 2 \\ 6 & 11 & 13 & 8 & 1 & 4 & 10 & 7 & 9 & 5 & 0 & 15 & 14 & 2 & 3 & 12\end{array}$

$\mathrm{S}_{8}$

$\begin{array}{llllllllllllllll}13 & 2 & 8 & 4 & 6 & 15 & 11 & 1 & 10 & 9 & 3 & 14 & 5 & 0 & 12 & 7\end{array}$ $\begin{array}{llllllllllllllll}1 & 15 & 13 & 8 & 10 & 3 & 7 & 4 & 12 & 5 & 6 & 11 & 0 & 14 & 9 & 2\end{array}$

$\begin{array}{llllllllllllllll}7 & 11 & 4 & 1 & 9 & 12 & 14 & 2 & 0 & 6 & 10 & 13 & 15 & 3 & 5 & 8\end{array}$

$\begin{array}{llllllllllllllll}2 & 1 & 14 & 7 & 4 & 10 & 8 & 13 & 15 & 12 & 9 & 0 & 3 & 5 & 6 & 11\end{array}$

The reader is referred to [3] for the official specification of these parameters. 


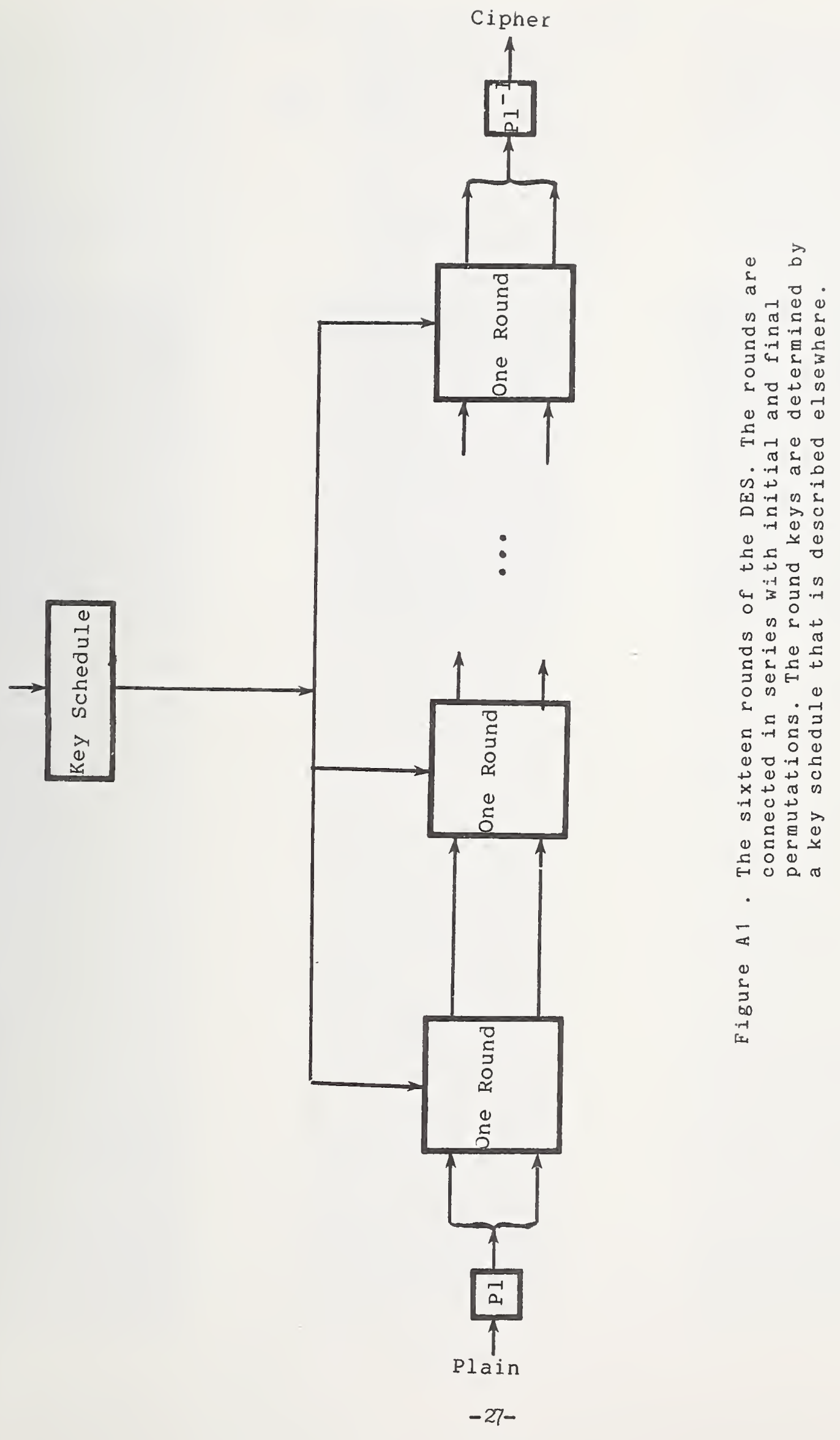


7. Appendix B: The DES Test Set

IP AND E TEST

KEY

PLA IN

CIPHER

0101010101010101 0101010101010101 0101010101010101 ø101010101010101 0101010101010101 0101010101010101 0101010101010101 0101010101010101 ø101010101010101 0101010101010101 0101010101010101 0101010101010101 0101010101010101 0101010101010101 0101010101010101 0101010101010101 0101010101010101 0101010101010101 0101010101010101 0101010101010101 0101010101010101 0101010101010101 0101010101010101 0101010101010101 0101010101010101 0101010101010101 0101010101010101 0101010101010101 0101010101010101 0101010101010101 0101010101010101 ด101010101010101 0101010101010101 0101010101010101 0101010101010101 0101010101010101 0101010101010101 0101010101010101 0101010101010101 0101010101010101
95F 8A 5E 5DD 31D9 $\emptyset$ DD 7F121CA 5015619 2E $86531 \emptyset 4 \mathrm{~F} 3834 \mathrm{EA}$ $4 \mathrm{BD} 388 \mathrm{FF} 6 \mathrm{CD} 81 \mathrm{D} 4 \mathrm{~F}$ 20B 9E 767 B $2 F B 1456$ $55579380 \mathrm{D} 77138 \mathrm{EF}$ 6CC 5DEFAAF $\emptyset 4512 \mathrm{~F}$ ØD 9F 279BA 5D 87260 D $9031 \mathrm{~B} 0271 \mathrm{BD} 5 \mathrm{~A} \emptyset \mathrm{A}$ $424250 B 37 C 3 D D 951$ B $8061 B 7 E C D 9 A 21$ E 5 F 15D ØF 286B 65BD 28 ADD ØCC 8D 6E 5DEBA I E 6D 5F 82752AD 63D I ECBFE 3BD 3F 591A 5E F 356834379D 165CD 2B 9F 982F $20037 \mathrm{FA} 9$ 889DE $068 \mathrm{~A} 16 \mathrm{~F}$ ØBE 6 E 19E 275D 846Al 298 329A 8ED523D 71AEC E 7FCE 22557D 23C 97 $12 \mathrm{~A} 9 \mathrm{~F} 5817 \mathrm{FF} 2 \mathrm{D} 65 \mathrm{D}$ A 484C 3AD 38DC 9C1 9 FBE ØØA 8A1EF 8AD7 2 $750 \mathrm{D} \emptyset 79407521363$ $64 \mathrm{FEED} 9 \mathrm{C} 724 \mathrm{C} 2 \mathrm{FAF}$ $\mathrm{F} \emptyset 2 \mathrm{~B} 263 \mathrm{~B} 328 \mathrm{E} 2 \mathrm{~B} 6$ Ø 9D64555A 9A10B852 D1 Ø6FF ØBED5255D 7 E1652C6B138C $64 \mathrm{~A} 5$ E $428581186 \mathrm{EC} 8 \mathrm{~F} 46$ AEB 5F 5EDE 22DIA 36 E 943D 7568AEC ØC 5C DF $98 \mathrm{C} 8276 \mathrm{~F} 54 \mathrm{~B} \emptyset 4 \mathrm{~B}$ $\mathrm{B} 160 \mathrm{E} 4680 \mathrm{~F} 6 \mathrm{C} 696 \mathrm{~F}$ $\mathrm{FA} 0752 \mathrm{~B} 07 \mathrm{D} 9 \mathrm{C} 4 \mathrm{AB} 8$ CA 3A 2B $036 \mathrm{DBC} 8502$ 5E $0905517 \mathrm{BB} 59 \mathrm{BCF}$ 814EEB 3B 91D 90726 4D 4 9DB1532919C9F

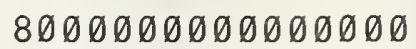
$4 \emptyset \emptyset \emptyset \emptyset \emptyset \emptyset \emptyset \emptyset \emptyset \emptyset \emptyset \emptyset \emptyset \emptyset \emptyset$ $2 \emptyset \emptyset \emptyset \emptyset \emptyset \emptyset \emptyset \emptyset \emptyset \emptyset \emptyset \emptyset \emptyset \emptyset \emptyset$

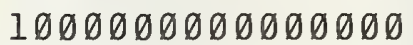

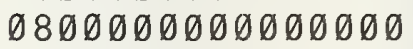
$\emptyset 4 \emptyset \emptyset \emptyset \emptyset \emptyset \emptyset \emptyset \emptyset \emptyset \emptyset \emptyset \emptyset \emptyset \emptyset$

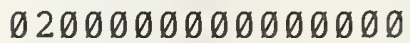

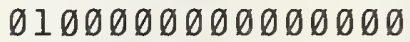

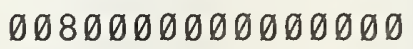

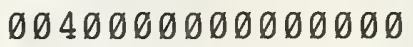
$\emptyset \emptyset 20 \emptyset \emptyset \emptyset \emptyset \emptyset \emptyset \emptyset \emptyset \emptyset \emptyset \emptyset \emptyset$

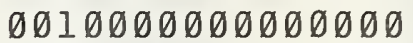

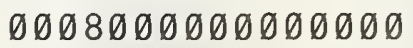

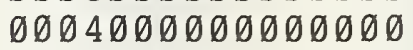

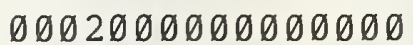

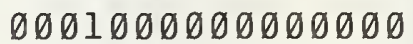

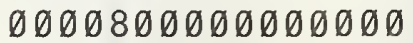

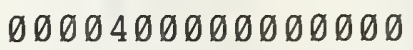
$\emptyset \emptyset \emptyset \emptyset 20 \emptyset \emptyset \emptyset \emptyset \emptyset \emptyset \emptyset \emptyset \emptyset \emptyset$

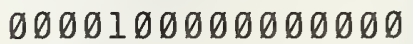

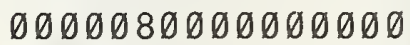

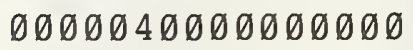

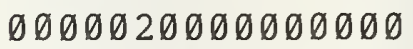

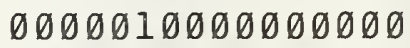

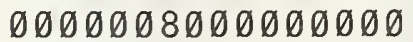

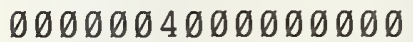

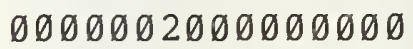

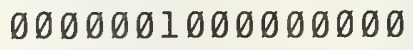

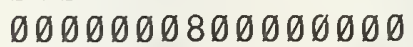

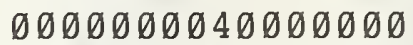

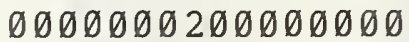

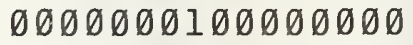

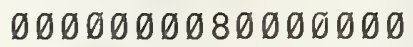

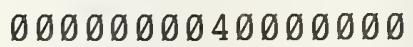

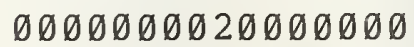
$\emptyset \emptyset \emptyset \emptyset \emptyset \emptyset \emptyset \emptyset 1 \emptyset, \emptyset \emptyset \emptyset \emptyset \emptyset$

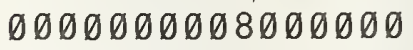

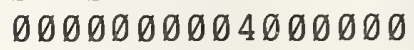

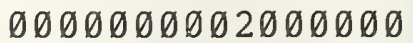

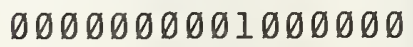


0101010101010101 0101010101010101 0101010101010101 0101010101010101 0101010101010101 0101010101010101 0101010101010101 0101010101010101 0101010101010101 0101010101010101 0101010101010101 0101010101010101 0101010101010101 0101010101010101 0101010101010101 0101010101010101 0101010101010101 0101010101010101 0101010101010101 0101010101010101 0101010101010101 0101010101010101 0101010101010101 0101010101010101
25EB 5FC 3F 8CF 0621 AB 6A 20C 0620D 1C 6F 79E $90 \mathrm{DBC} 98 \mathrm{~F} 92 \mathrm{CCA}$ 866ECEDD $8072 \mathrm{BB} \emptyset \mathrm{E}$ 8B 54536 F 2F 3E 64 A 8 EA51D3975595B 86B CAFFC6AC 4 54 2DE 31 8DD 45A2DDF $90796 \mathrm{C}$ $1029 \mathrm{D} 55 \mathrm{E} 880 \mathrm{EC} 2 \mathrm{D} \emptyset$ 5D 86CB23639DBEA 9 1D ICA 853AE 7C ØC 5F CE 332329248 F 3228 $8405 \mathrm{D} 1 \mathrm{ABE} 24 \mathrm{FB} 942$ E 643D $78090 \mathrm{CA} 4207$ 48221 B 9937748 A 23 DD 7C øBBD61FAFD 54 2FBC 291A57 ØDB 5C 4 E $07 C 30 D 7 E 4 E 26 E 12$ ๑ 953E $2258 \mathrm{E} 8 \mathrm{E} 90 \mathrm{~A} 1$ 5B 711BC 4CEEBF 2E E CC083F lE 6D 9E 85F 6 D 2FD8867D50D 2DFE Ø6E7EA 22CE $927 \emptyset 8 \mathrm{~F}$ $166 \mathrm{~B} 40 \mathrm{~B} 44 \mathrm{ABA} 4 \mathrm{BD} 6$

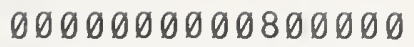
0000000000400000

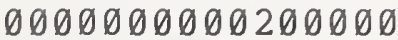
0000000000100000 0000000000080000

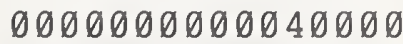
$\emptyset \emptyset 0000 \emptyset 0 \emptyset 0020000$

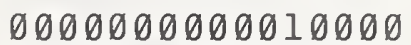
0000000000008000

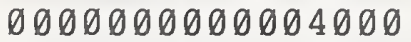
0000000000002000 ๑000000000001000 ๑000000000000800

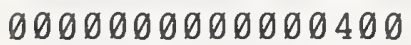

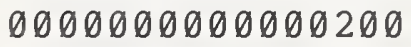

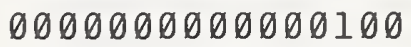
0000000000000080

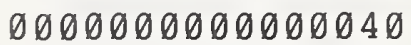

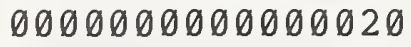
๑000000000000010 0000000000000008

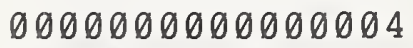
0000000000000002 0000000000000001 
8001010101010101 4001010101010101 2001010101010101 1001010101010101 0801010101010101 0401010101010101 0201010101010101 $\emptyset 180010101010101$ 0140010101010101 Ø120010101010101 0110010101010101 0108010101010101 0104010101010101 0102010101010101 0101800101010101 $\emptyset 101400101010101$ $\emptyset 101200101010101$ 0101100101010101 0101080101010101 0101040101010101 0101020101010101 0101018001010101 0101014001010101 0101012001010101 0101011001010101 0101010801010101 0101010401010101 0101010201010101 0101010180010101 0101010140010101 Ø101010120010101 0101010110010101 0101010108010101 Ø101010104010101 0101010102010101 0101010101800101 0101010101400101 0101010101200101 0101010101100101 $\emptyset 101010101080101$ 0101010101040101 0101010101020101 $\emptyset \emptyset \emptyset \emptyset \emptyset \emptyset \emptyset \emptyset \emptyset \emptyset \emptyset \emptyset \emptyset \emptyset \emptyset \emptyset$ $\emptyset \emptyset \emptyset \emptyset \emptyset \emptyset \emptyset \emptyset \emptyset \emptyset \emptyset \emptyset \emptyset \emptyset \emptyset \emptyset$ $\emptyset \emptyset \emptyset \emptyset \emptyset \emptyset \emptyset \emptyset \emptyset \emptyset \emptyset \emptyset \emptyset \emptyset \emptyset \emptyset$ $\emptyset \emptyset \emptyset \emptyset \emptyset \emptyset \emptyset \emptyset \emptyset \emptyset \emptyset \emptyset \emptyset \emptyset \emptyset \emptyset$ $\emptyset \emptyset \emptyset \emptyset \emptyset \emptyset \emptyset \emptyset \emptyset \emptyset \emptyset \emptyset \emptyset \emptyset \emptyset \emptyset$ $\emptyset \emptyset \emptyset \emptyset \emptyset \emptyset \emptyset \emptyset \emptyset \emptyset \emptyset \emptyset \emptyset \emptyset \emptyset \emptyset$ $\emptyset \emptyset \emptyset \emptyset \emptyset \emptyset \emptyset \emptyset \emptyset \emptyset \emptyset \emptyset \emptyset \emptyset \emptyset \emptyset$ $\emptyset \emptyset \emptyset \emptyset \emptyset \emptyset \emptyset \emptyset \emptyset \emptyset \emptyset \emptyset \emptyset \emptyset \emptyset \emptyset$

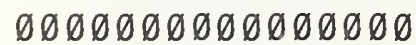
$\emptyset \emptyset \emptyset \emptyset \emptyset \emptyset \emptyset \emptyset \emptyset \emptyset \emptyset \emptyset \emptyset \emptyset \emptyset \emptyset$ $\emptyset \emptyset \emptyset \emptyset \emptyset \emptyset \emptyset \emptyset \emptyset \emptyset \emptyset \emptyset \emptyset \emptyset \emptyset \emptyset$ $\emptyset \emptyset \emptyset \emptyset \emptyset \emptyset \emptyset \emptyset \emptyset \emptyset \emptyset \emptyset \emptyset \emptyset \emptyset \emptyset$ $\emptyset \emptyset \emptyset \emptyset \emptyset \emptyset \emptyset \emptyset \emptyset \emptyset \emptyset \emptyset \emptyset \emptyset \emptyset \emptyset$ $\emptyset \emptyset \emptyset \emptyset \emptyset \emptyset \emptyset \emptyset \emptyset \emptyset \emptyset \emptyset \emptyset \emptyset \emptyset \emptyset$ $\emptyset \emptyset \emptyset \emptyset \emptyset \emptyset \emptyset \emptyset \emptyset \emptyset \emptyset \emptyset \emptyset \emptyset \emptyset \emptyset$ $\emptyset \emptyset \emptyset \emptyset \emptyset \emptyset \emptyset \emptyset \emptyset \emptyset \emptyset \emptyset \emptyset \emptyset \emptyset \emptyset$ $\emptyset \emptyset \emptyset \emptyset \emptyset \emptyset \emptyset \emptyset \emptyset \emptyset \emptyset \emptyset \emptyset \emptyset \emptyset \emptyset$ $\emptyset \emptyset \emptyset \emptyset \emptyset \emptyset \emptyset \emptyset \emptyset \emptyset \emptyset \emptyset \emptyset \emptyset \emptyset \emptyset$ $\emptyset \emptyset \emptyset \emptyset \emptyset \emptyset \emptyset \emptyset \emptyset \emptyset \emptyset \emptyset \emptyset \emptyset \emptyset \emptyset$ $\emptyset \emptyset \emptyset \emptyset \emptyset \emptyset \emptyset \emptyset \emptyset \emptyset \emptyset \emptyset \emptyset \emptyset \emptyset \emptyset$ $\emptyset \emptyset \emptyset \emptyset \emptyset \emptyset \emptyset \emptyset \emptyset \emptyset \emptyset \emptyset \emptyset \emptyset \emptyset \emptyset$ $\emptyset \emptyset \emptyset \emptyset \emptyset \emptyset \emptyset \emptyset \emptyset \emptyset \emptyset \emptyset \emptyset \emptyset \emptyset \emptyset$

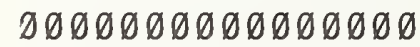
$\emptyset \emptyset \emptyset \emptyset \emptyset \emptyset \emptyset \emptyset \emptyset \emptyset \emptyset \emptyset \emptyset \emptyset \emptyset \emptyset$ $\emptyset \emptyset \emptyset \emptyset \emptyset \emptyset \emptyset \emptyset \emptyset \emptyset \emptyset \emptyset \emptyset \emptyset \emptyset \emptyset$ $\emptyset \emptyset \emptyset \emptyset \emptyset \emptyset \emptyset \emptyset \emptyset \emptyset \emptyset \emptyset \emptyset \emptyset \emptyset \emptyset$ $\emptyset 000000000000000$ $\emptyset \emptyset \emptyset \emptyset \emptyset \emptyset \emptyset \emptyset \emptyset \emptyset \emptyset \emptyset \emptyset \emptyset \emptyset \emptyset$ $\emptyset \emptyset \emptyset \emptyset \emptyset \emptyset \emptyset \emptyset \emptyset \emptyset \emptyset \emptyset \emptyset \emptyset \emptyset \emptyset$ $\emptyset \emptyset \emptyset \emptyset \emptyset \emptyset \emptyset \emptyset \emptyset \emptyset \emptyset \emptyset \emptyset \emptyset \emptyset \emptyset$ $\emptyset \emptyset 0 \emptyset \emptyset \emptyset \emptyset \emptyset \emptyset \emptyset \emptyset \emptyset \emptyset \emptyset \emptyset \emptyset$ $\emptyset \emptyset \emptyset \emptyset \emptyset \emptyset \emptyset \emptyset \emptyset \emptyset \emptyset \emptyset \emptyset \emptyset \emptyset \emptyset$ $\emptyset \emptyset \emptyset \emptyset \emptyset \emptyset \emptyset \emptyset \emptyset \emptyset \emptyset \emptyset \emptyset \emptyset \emptyset \emptyset$ $\emptyset \emptyset \emptyset \emptyset \emptyset \emptyset \emptyset \emptyset \emptyset \emptyset \emptyset \emptyset \emptyset \emptyset \emptyset \emptyset$ $\emptyset \emptyset \emptyset \emptyset \emptyset \emptyset \emptyset \emptyset \emptyset \emptyset \emptyset \emptyset \emptyset \emptyset \emptyset \emptyset$ $\emptyset \emptyset \emptyset \emptyset \emptyset \emptyset \emptyset \emptyset \emptyset \emptyset \emptyset \emptyset \emptyset \emptyset \emptyset \emptyset$ 0000000000000000 $\emptyset \emptyset \emptyset \emptyset \emptyset \emptyset \emptyset \emptyset \emptyset \emptyset \emptyset \emptyset \emptyset \emptyset \emptyset \emptyset$ $\emptyset \emptyset \emptyset \emptyset \emptyset \emptyset \emptyset \emptyset \emptyset \emptyset \emptyset \emptyset \emptyset \emptyset \emptyset \emptyset$ $\emptyset \emptyset \emptyset \emptyset \emptyset \emptyset \emptyset \emptyset \emptyset \emptyset \emptyset \emptyset \emptyset \emptyset \emptyset \emptyset$ $\emptyset \emptyset \emptyset \emptyset \emptyset \emptyset \emptyset \emptyset \emptyset \emptyset \emptyset \emptyset \emptyset \emptyset \emptyset \emptyset$

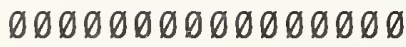

95A 8D 72813DAA 94D ๑EEC 1487DD 8C 26D 5 7AD 16F FB 79C 45926 D $3746294 \mathrm{CA} 6 \mathrm{~A} 6 \mathrm{CF} 3$ $809 \mathrm{~F} 5 \mathrm{~F} 873 \mathrm{ClFD} 761$ C $\oslash 2 \mathrm{FAFFEC} 989 \mathrm{D}$ IFC $4615 A A I D 33 E 72 F 10$ $2055123350 \mathrm{C} \emptyset 0858$ DF 3B 99D $6577397 \mathrm{C} 8$ 31FEl 7369B $5288 \mathrm{C} 9$ DFDD 3CC 64DAE 1642 $178 C$ 83CE 2B 399D 94 $50 \mathrm{~F} 636324 \mathrm{~A} 9 \mathrm{~B} 7 \mathrm{~F} 80$ $\mathrm{A} 8468 \mathrm{EE} 3 \mathrm{BC} 18 \mathrm{~F} \emptyset 6 \mathrm{D}$ A2DC 9E 92 FD 3CDE 92 CAC $09 F 797 D 031287$ 90 BA 680 В 22 АEB 525 CE 7A 24F 35 ØE 280B 6 $882 \mathrm{BFF} \emptyset \mathrm{AA} \emptyset 1 \mathrm{~A} \emptyset \mathrm{B} 87$ 2561Ø288924511C2 C71516C29C75D 170 $5199 \mathrm{C} 29 \mathrm{~A} 52 \mathrm{C} 9 \mathrm{~F} \oslash 59$ C 22F ØA 294A 7IF 29F EE371483714CØ2EA A $81 F B D 448$ F 9 E $522 \mathrm{~F}$ $4 \mathrm{~F} 644 \mathrm{C} 92 \mathrm{E} 1$ 92DFED IAFA 9A 6 6A 6DF 9 2AE B 3C 1CC 7 15CB 8 79D 8 $19 \mathrm{D} 032 \mathrm{E} 64 \mathrm{AB} \emptyset \mathrm{BD} 8 \mathrm{~B}$ 3CFAA7A 7DC 8720DC B 726 5F 7F 4 47AC 6F 3 9DB 73B 3C $0 \mathrm{D} 163 \mathrm{~F} 54$ 8181B 65BABF 4A 975 93C $9 B 64042 \mathrm{EAA} 240$ 5570530829705592 $8638809 \mathrm{E} 878787 \mathrm{~A} 0$ 41B 9A 79AF 79AC $2 \varnothing 8$ 7A 9BE 4 2F $2009 A 892$ $29038 D 56 B A 6 D 2745$ $5495 \mathrm{C} 6 \mathrm{ABF} 1 \mathrm{E} 5 \mathrm{DF} 5 \mathrm{I}$ AEI 3DBD 561488933 $\emptyset 24$ D IFFA8 904 E 389 
0101010101018001 Ø101010101014001 0101010101012001 0101010101011001 0101010101010801 ๑101010101010401 0101010101010201 ด101010101010180 Ø101010101010140 0101010101010120 0101010101010110 0101010101010108 0101010101010104 0101010101010102

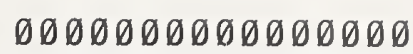

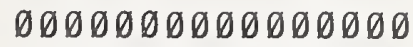

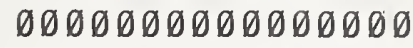

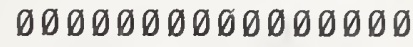

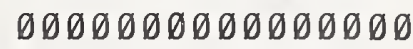

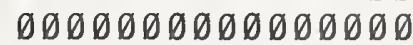

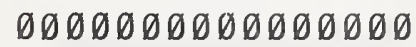

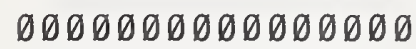

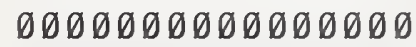

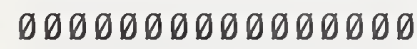

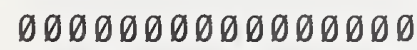

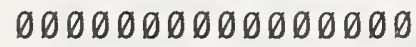

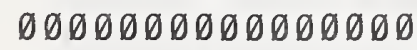

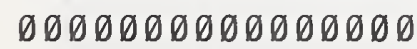

D1399712F99BF02E 14C ID 7C ICFFEC 79E IDE 5279DAE 3BED6F E941A33F85501303 DA99DBBC9AØ3F 379 B 7FC9 2F 9 ID 8E 92 E 9 AE 8E 5CAA 3CA 0 4E 85 9CC 62 DF 4 3B 6EED 74 D 863DBB 5C59A $91 \mathrm{AD}$ AlAB 2190545B91D7 Ø87504IE64C57ØF7 5A 594528BEBEF $1 C C$ FCDB $3291 \mathrm{DE} 21 \mathrm{~F} \emptyset \mathrm{C} \emptyset$ 869EFD 7F 9F 265A日9 
1046913489980131 1007103489988020 $10071034 C 8980120$ $104610348998802 \emptyset$ 1086911519190101 1086911519580101 $5107 \mathrm{~B} 01519580101$ $1007 \mathrm{~B} 01519190101$ 3107915498080101 3107919498080101 $10079115 B 9080140$ 3107911598080140 1007DØ1589980101 9107911589980101 9107D01589190101 1007D01598980120 1007940498190101 0107910491190401 Ø107910491190101 Ø107940491190401 $19079210981 \mathrm{ADI01}$ 1007911998190801 $10079119981 \mathrm{~A} 0801$ 1007921098190101 $100791159819010 \mathrm{~B}$ 1004801598190101 1004801598190102 1004801598190108 1002911598100104 1002911598190104 1002911598100201 1002911698100101

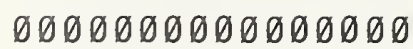

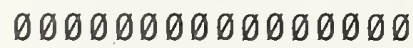

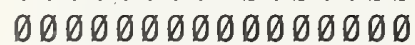

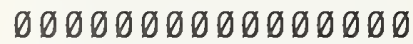

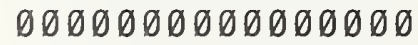

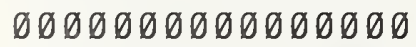

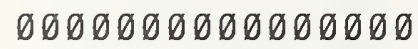

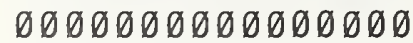

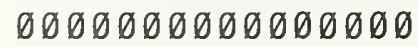
๑๐

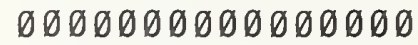

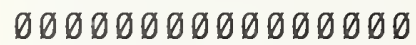

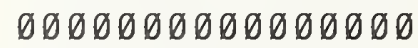

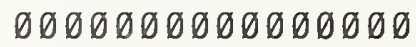

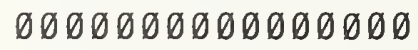

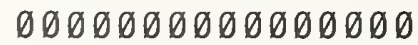

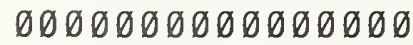

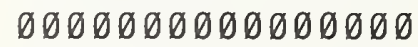

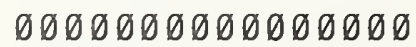

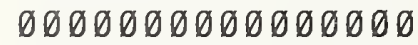

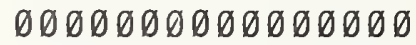

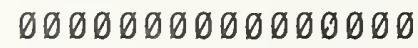

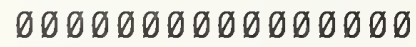

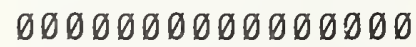

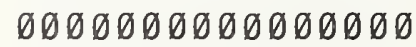

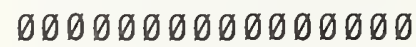

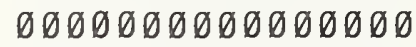

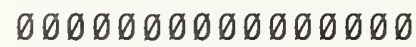

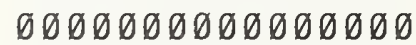

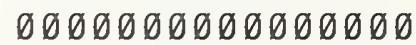

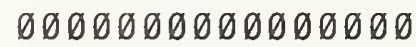

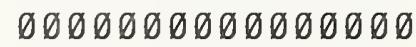

88D 55E 54F 54C $97 \mathrm{~B} 4$ ØСØССØØС 83ЕA48FD 83BC8EF 3A 6570183 DF 725DCAD 9 4EA 2E 9 E 652B 53B 5 50BE8B Ø AF $527120 \mathrm{C} 485 \mathrm{CBB} \emptyset$ Ø $\emptyset 4 C E 393 \mathrm{DB} 926 \mathrm{D} 5$ C9F冋ØFFC $74 \emptyset 79067$ 7CFD82A 593252B 4E CB 49A 2F 9E 91363 E 3 Ø 4 6 6А 9A 6АВ $43399 \mathrm{AE}$ 6CB 77361 IDCA9ADA 67FD21C17DBB 5D 70 9592CB 4110430787 A 6B 7FF 68A $318 D D D 3$ 4D102196C $914 \mathrm{CA} 16$ 2DFA9F 4573594965 B $46604816 \mathrm{C} \emptyset \mathrm{E} 0774$ $6 \mathrm{E} 7 \mathrm{E} 6221 \mathrm{~A} 4 \mathrm{~F} 34 \mathrm{E} 87$ AA 85E 74643233199 2E 5A 1 9DB 4D $1962 \mathrm{D} 6$ 23A 866A 809D 30894 D812D961F冋17D 320 Ø55605816E58608F $\mathrm{ABD} 88 \mathrm{E} 8 \mathrm{~B} 1 \mathrm{~B} 7716 \mathrm{~F} 1$ 537AC95BE69DAlEl AED $6 \mathrm{~F}$ 6AE 3C 25CDD8 B 3E 35A 5EE 5 3E 7B 8D 51C79C 71921A 2EF 8 E 2F 5728F $0995013 \mathrm{C}$ IAEAC 39A 6IF ØA 464 
19 Key data pairs which exercise every s-box entry.

KEY

PLA IN

CIPHER

7CA110454AIA6E 57 $\emptyset 131 D 9619 D C 1376 \mathrm{E}$ ๑A 1133E 4AØB 2686 $3849674 \mathrm{C} 2602319 \mathrm{E}$ Ø 4B $915 B A 43 F E B 5 B 6$ $\emptyset 113 \mathrm{~B} 970 \mathrm{FD} 34 \mathrm{~F} 2 \mathrm{CE}$ Ø17ØF 1754 68FB 5E 6 43297FAD 38E373FE $\emptyset 7 A 7137 \emptyset 4$ 5DA2A 16 $\emptyset 46891 \emptyset 4 \mathrm{C} 2 \mathrm{FD} 3 \mathrm{~B} 2 \mathrm{~F}$ 37D $06 \mathrm{BB} 516 \mathrm{CB} 7546$ $1 \mathrm{~F} \emptyset 826 \emptyset \mathrm{DlAC} 2465 \mathrm{E}$ $584023641 \mathrm{ABA} 6176$ $025816164629 B 007$ $49793 \mathrm{EBC} 79 \mathrm{~B} 3258 \mathrm{~F}$ $4 \mathrm{FB} \emptyset 5 \mathrm{E} 1515 \mathrm{AB} 73 \mathrm{~A} 7$ 49E 95D 6D 4CA 22 9BF Ø1831øDC4ø9B26D 6 IC $587 \mathrm{FlCl} 3924 \mathrm{FEF}$
Ø1A1D6D 039776742 5CD54CA 83DEF 57DA Ø248D 438ø6F 67172 514 54B 582DDF 4 ØA $42 \mathrm{FD} 443059577 \mathrm{FA} 2$ Ø59B 5E $\oslash 851 C F 143 \mathrm{~A}$ $\emptyset 756 \mathrm{D} 8 \mathrm{E} \emptyset 774761 \mathrm{D} 2$ 7625].4B 829BF 486A 3BDD $1190493728 \emptyset 2$ 26955F 6835AF609A $164 \mathrm{D} 5 \mathrm{E} 404 \mathrm{~F} 275232$ $6 \mathrm{~B} 056 \mathrm{E} 18759 \mathrm{~F} 5 \mathrm{CCA}$ $\emptyset \emptyset 4 \mathrm{BD} 6 \mathrm{EF} \emptyset 9176062$ $480 \mathrm{D} 390 \emptyset 6 \mathrm{EE} 762 \mathrm{~F} 2$ $437540 \mathrm{C} 8698 \mathrm{~F} 3 \mathrm{CFA}$ $\emptyset 72 D 43 A \emptyset 77 \emptyset 75292$ ๑2FE55778117F $12 \mathrm{~A}$ 1D 9D 5C 5018F 728C 2 305532286 D 6F 295A
69ØF 5BØD9A 26939B 7A 389D 10354BD 271 868EBB5ICAB 4599A $7178876 \mathrm{E} 01 \mathrm{~F} 19 \mathrm{~B} 2 \mathrm{~A}$ AF 37FB 421F 8C 4095 86A560F1øEC6D85B

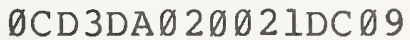
EA 676B 2CB 7DB 2B 7A DFD6 4A815CAF 1AØF 5C 513C 9C $4886 C 088$ $\emptyset$ A 2AEEAE $3 \mathrm{~F} \mathrm{~F} 4 \mathrm{AB} 77$ EF 1BFØ 3E 5DFA 575A 88BF ØDB 6D 7ØDEE 56 AlF $9915541020 B 56$ 6FBF ICAFCFFD 556 2F 22E $49 B A B 7 C A 1 A C$ 5A 6B $612 \mathrm{CC} 26 \mathrm{CCE} 4 \mathrm{~A}$ $5 \mathrm{~F} 4 \mathrm{C} \emptyset 38 \mathrm{ED} 12 \mathrm{~B} 2 \mathrm{E} 4 \mathrm{I}$ 63FACØDØ 34D 9F 793 
A manufacturer providing his own interface logic should use the following description and attached diagrams. In some cases, it will be relatively easy to provide hardwired logic that will make the device appear to be identical to the NBS device. However, there may be cases where it will not be feasible to make the device appear identical without software modifications in the microcomputer. In these cases, NBS personnel will make the necessary changes on a cost reimbursable basis.

\section{Interface Design}

The interface uses TTL logic levels (high-level output voltage of at least plus 2.4 volts and low-level of not more than plus 0.4 volts). The cabling normally provides a twisted pair return on three control lines to minimize the effect of noise. If further noise problems should arise, there are connector pins already allocated for twisted pair returns on the other lines. The connector uses an ELCO plug, part number $\emptyset \emptyset-8 \emptyset 16-\emptyset 56-\emptyset \emptyset \emptyset-819$. In most cases it will be easier if NBS provides the connector plug and wires it as por the pin assignments of the proprietary device. If desired, the submitter may use a different connector, provided that he supplies NBS with a mate to the connector for cabling to the ELCO on the NBS microcomputer.

The 1 ines used in the interface are shown in figure $\mathrm{Cl}$ and salient interface logic in figure $\mathrm{C} 2$. These lines are used for transferring a byte of data or key into the device from the microcomputer, for transferring a byte of data from the device back to the microcomputer and for various other control functions.

The mode of operation is controlled by the two lines: DATA/KEY and ENCIPHER/DECIPHER DATA. These levels will be stationary during a given operation. Thus, the proprietary device may either sample them at the time the first byte is loaded (data or key) or merely use them as levels for control of the process. (NBS uses the first alternative in its implementation to avoid the chance of any noise on the lines causing a malfunction.) The DATA/KEY line is low when a block of data is to be enciphered or deciphered. It is high when the key is entered. The ENCIPHER/DECIPHER DATA I ine is examined by the device only when data is to be enciphered or deciphered; otherwise it must be ignored. The key is 
always loaded in the clear in the validation tests, so any proprietary features for enciphering or deciphering of the key should be inactive during the tests. (However, each option of the proprietary device may be tested by making special arrangements with NBS.)

The RESET EXCEPT KEY level is set by the microcomputer program and then reset by a subsequent instruction. It is used to reset the controls in the device. It may, optionally, be used to reset the LR Register, though this is not necessary. The RESET ALL signal (level) was used in the NBS implementation as a convenierce for demonstration purposes and need not be implemented.

PARITY ERROR is a level from the proprietary device that indicates that one or more bytes of the key have even parity. However, it does not have to be implemented. Some devices may have available additional status indicators like BUSY and CONTROL ERROR. The tests do not make use of these indicators.

The 1 ines for loading a byte of data or key into the device are DATA READY 1, its twisted pair return and the 8 INPUT lines. The NBS microcomputer sets up the 8 INPUT lines and, in a subsequent instruction, fires a one shot to give an approximate one microsecond pulse for DATA READY 1. The device should use DATA READY 1 to strobe the 8 INPUT lines into the device. No response from the device to the microcomputer is needed. The 8 INPUT lines should be loaded as data or as key depending on the status of the DATA/KEY control line described previously. This process is repeated for each of the 8 bytes required for the 64 bits of data or key to be loaded into the device.

The iines for transferring a byte of data back to the microcomputer are DATA READY 2, ACCEPT 2, their twisted pair returns, and the 8 OUTPUT 1 ines. This transfer is asynchronous due to the much slower speed of the microcomputer. The sequence is: DATA READY 2 goes active (high) from the device after the 8 OUTPUT lines are stabilized; the DATA READY 2 line is polled by the program; a subsequent instruction fires a one shot to give an approximately one microsecond pulse for ACCEPT 2 (active low) to the device; and the device brings DATA READY 2 inactive (low) in response to ACCEPT 2. This process is repeated for each of the 8 bytes required for a 64 bit block transfer.

The input data, input key and output data byte numbering are shown in the figures $\mathrm{C} 3$ and $\mathrm{C} 4$. 


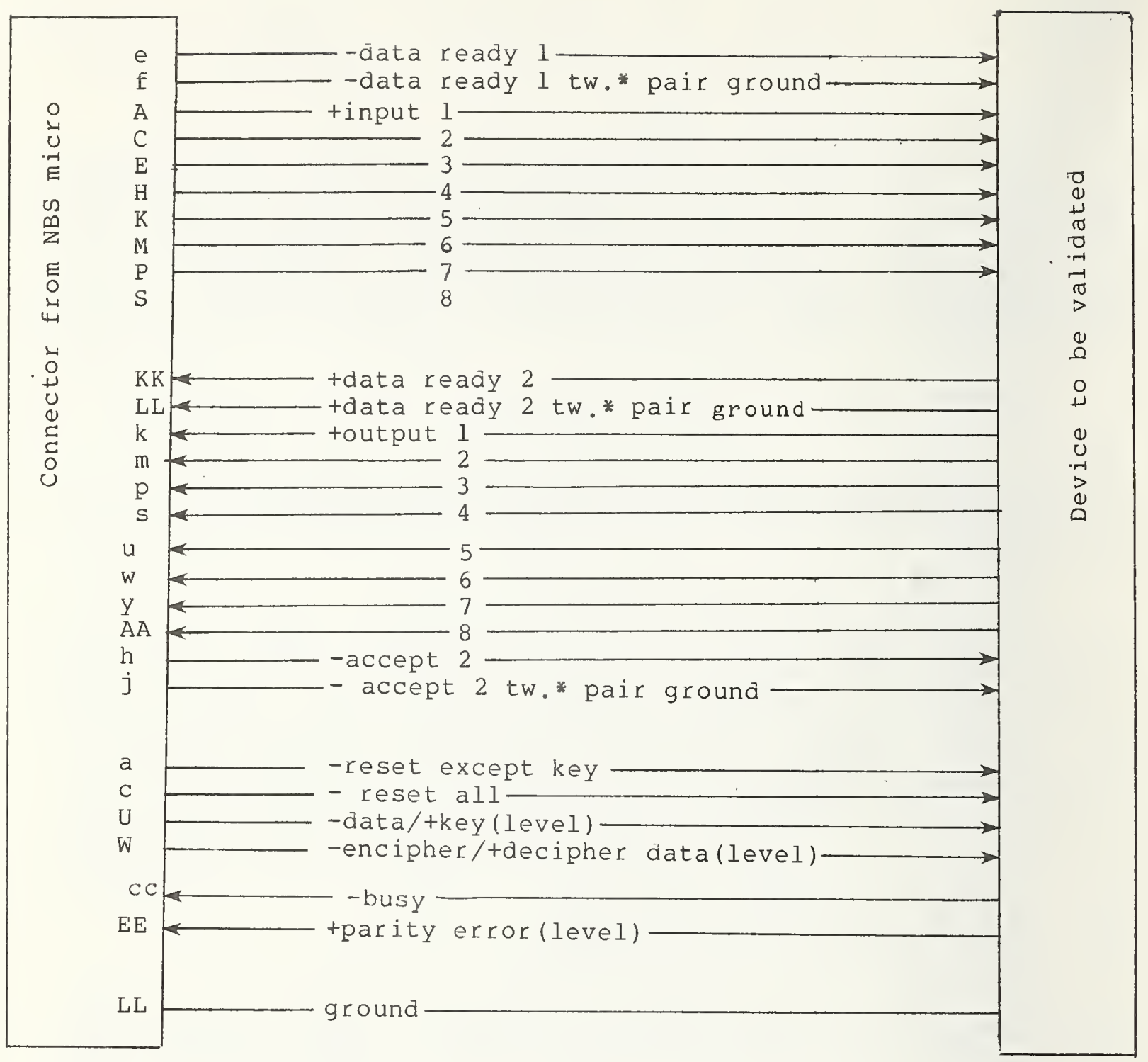

*twisted

Figure Cl. Interface line specifications or the NBS data encryption testbed.

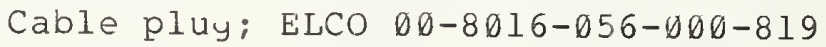

Chassis socket: ELCO $\emptyset \emptyset-8 \emptyset 16-\emptyset 56-\emptyset \emptyset \emptyset-7 \emptyset 7$ 

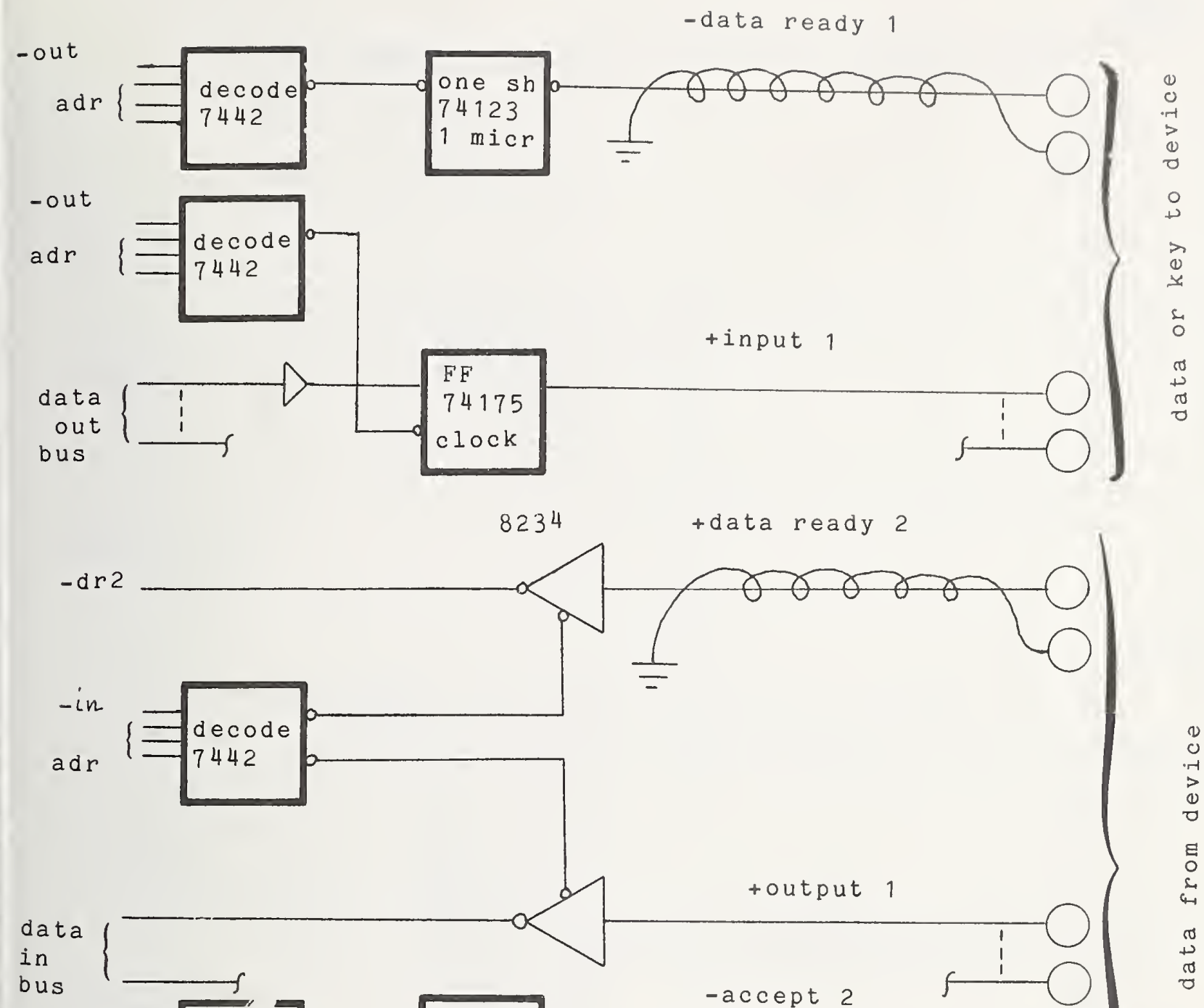

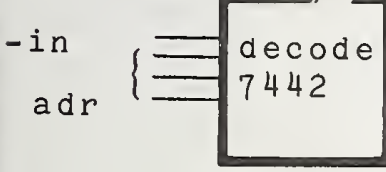

one sh

74123

$1 \mathrm{micr}$

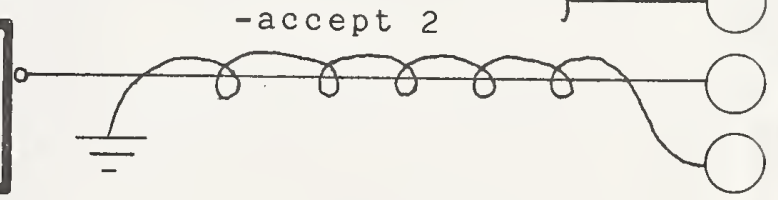

-in

a d

data

out

bus
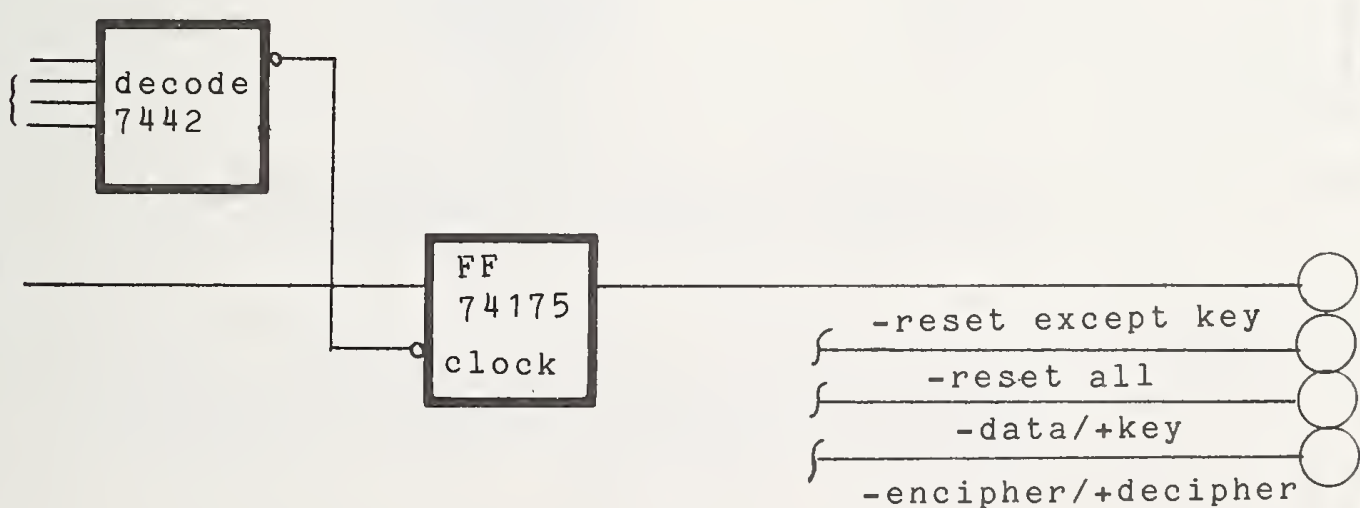

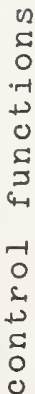

Figure C2. The logic diagram for the NBS data encryption testbed interface. 
DATA

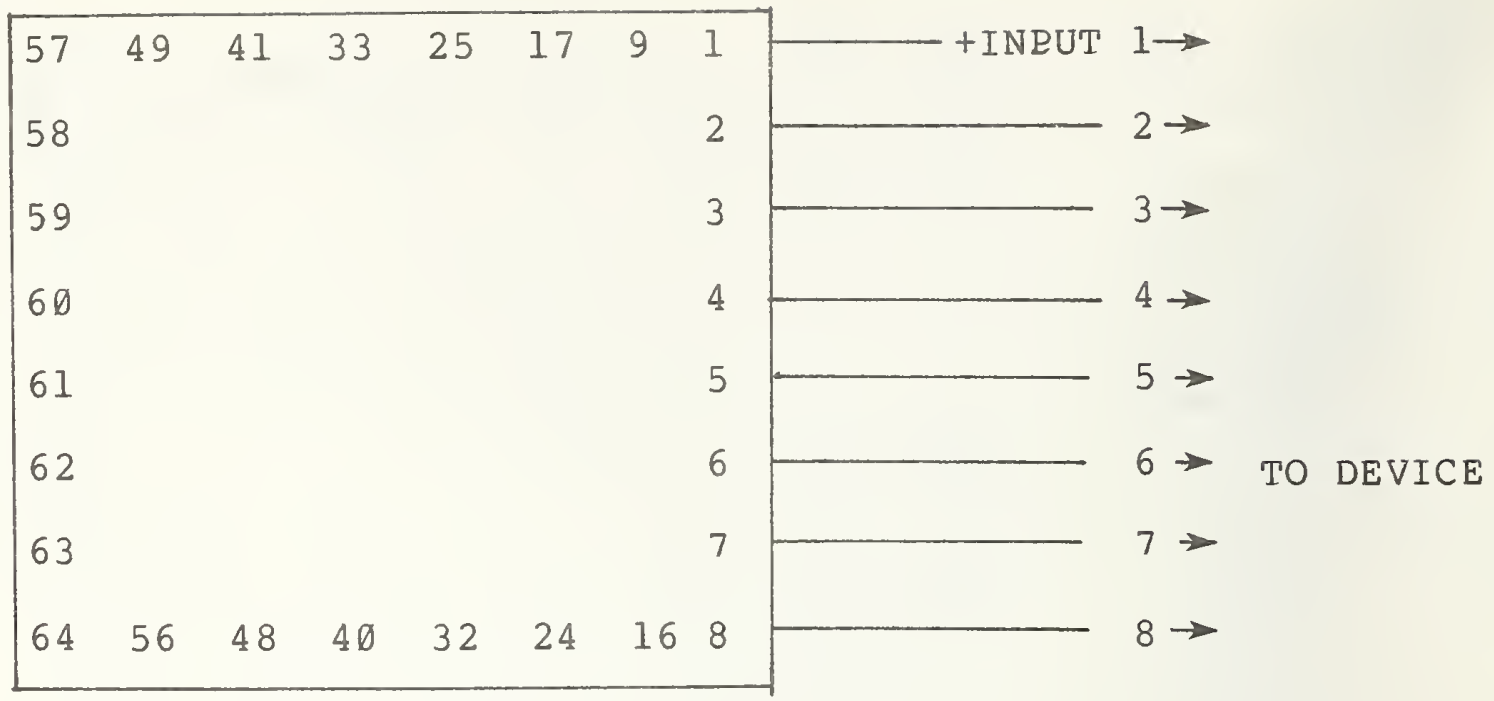

KEY

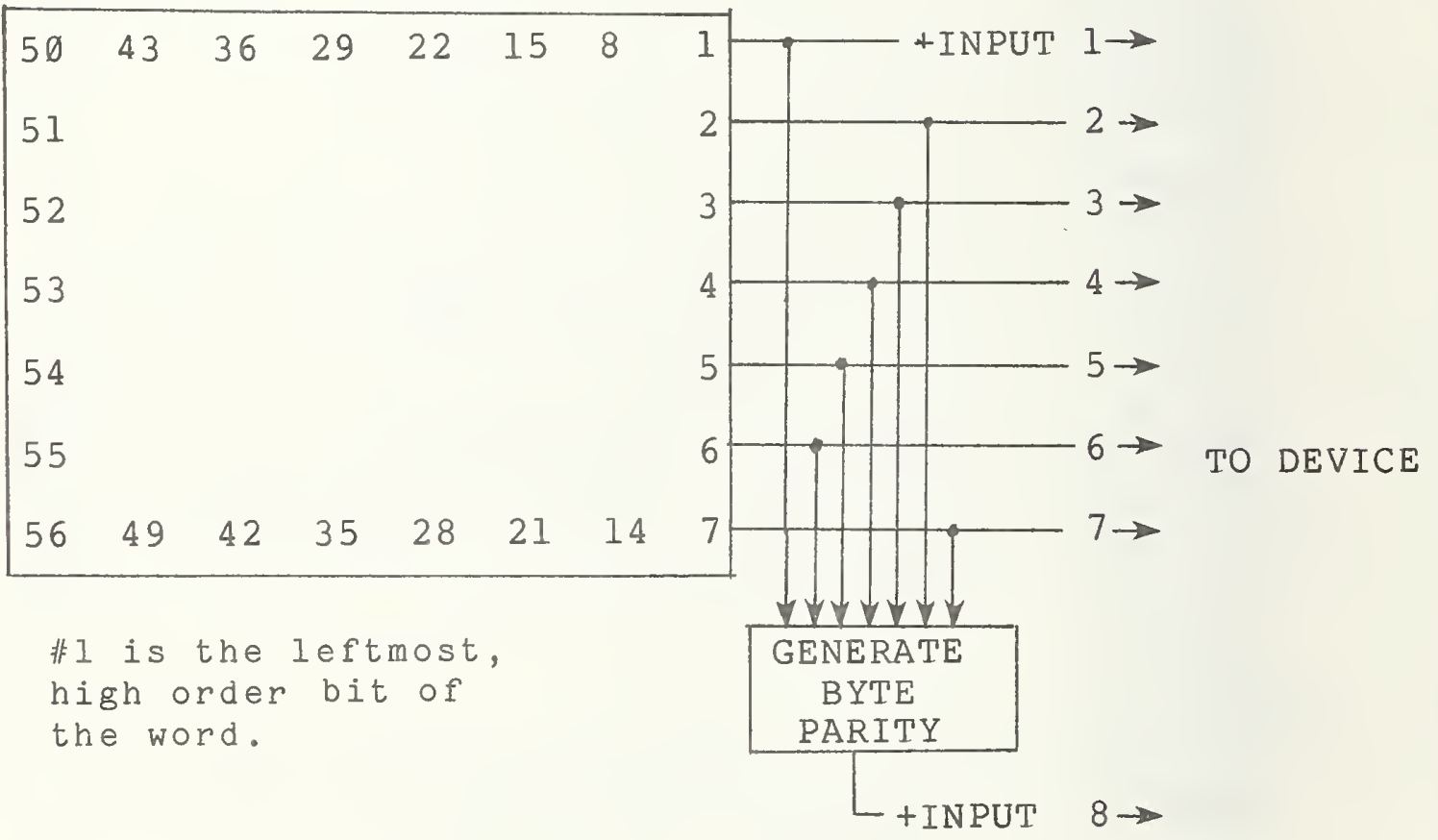

Figure C3. Input data and input key byte numbering for the NBS data encryption standard testbed interface. 


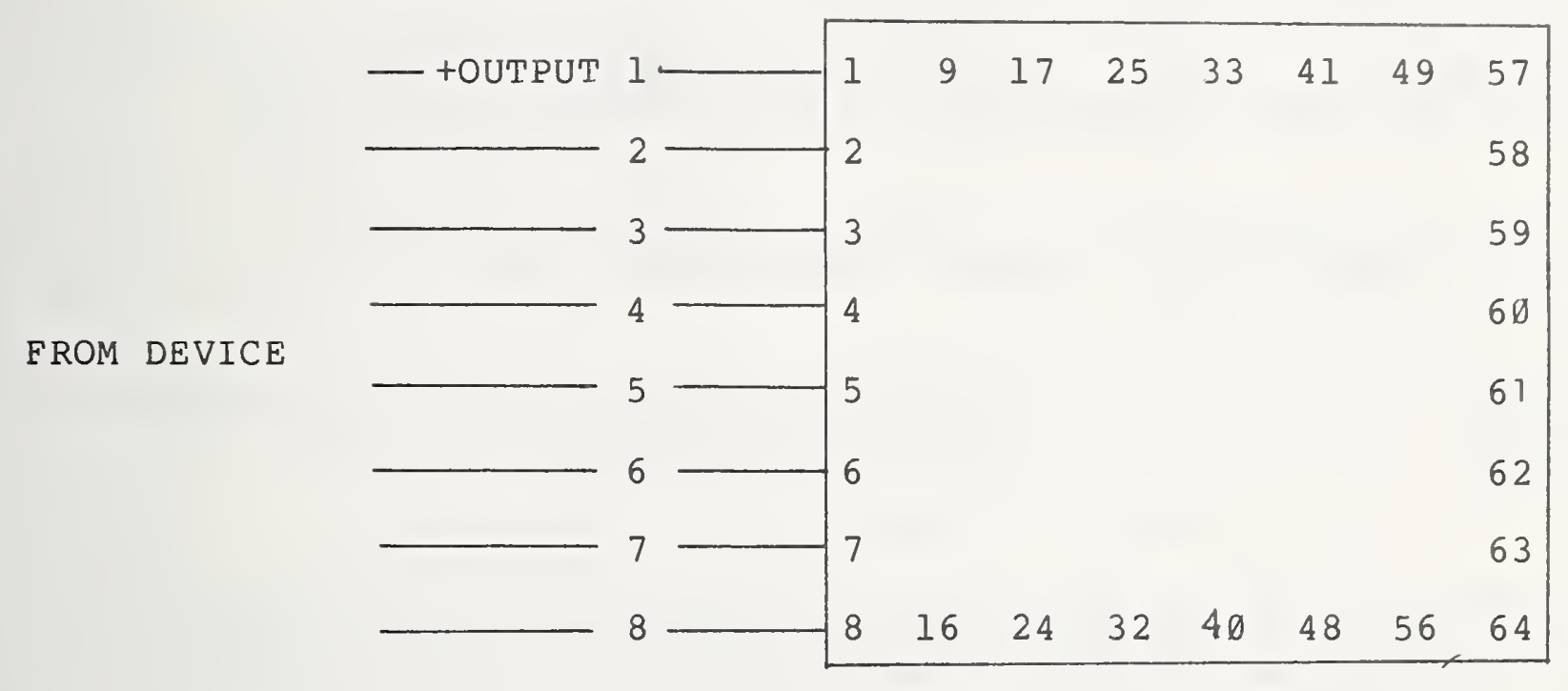

$\# 1$ is the leftmost,high order bit of the 64-bit data block.

Fiqure C4. Output data byte numbering for the NBS data encryption testbed interface. 
REFERENCES

1. Meyer, C., Enciphering Data for Secure Transmission, Computer Design, (April, 1974)129-34.

2. Meyer, C. and $W$. Tuchman, Pseudo-random Codes Can Be Cracked, Elect. Design,vol. 23 (1972)74-6.

3. Data Encryption Standard, FIPS PUB 46, Jan. 15, 1977.

4. Grossman, E. and B. Tuckerman, Analysis of a Feistel-like Cipher Weakened by Having No Rotating Key, IBM Rpt c6375, 1977.

5. Gait, J., A New Non-Linear Pseudo-random Number Generator, IEEE Transactions on Software Engineering, Sept.,1977.

6. Bright, H. and R. Ennison, Cryptography Using Modular Software Elements, National Computer Conf,,1976,113-23.

7. Calibration and Test Services of NBS, Spec.Pub. 250,1970.

8. DES Guidelines, NBS Special Publication 5øø-xx (In preparation). 
NBS.114A (REV.7.73)

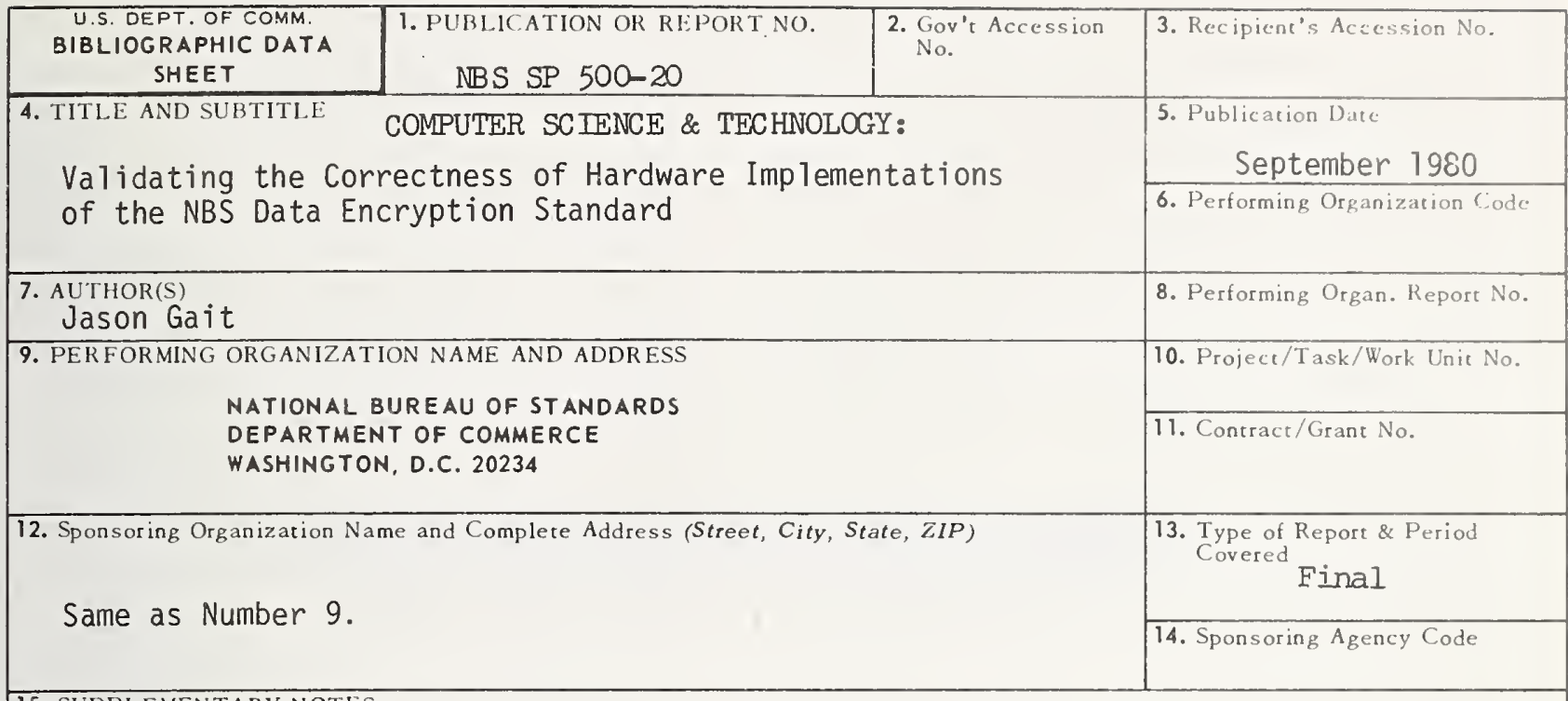

15. SUPPLEMENTARY NOTES

Library of Congress Catalog Card Number: 77-16067

16. ABSTRACT (A 200-word or less factual summary of most significant information. If document includes a significant bibliography or literature survey, mention it here.)

This publication describes the design and operation of the NBS testbed that is used for the validation of hardware implementations of the Federal Information Processing Data Encryption Standard (DES). A particular implementation is verified if it correctly performs a set of 291 test cases that have been defined to exercise every basic element of the algorithm. As a further check on the correctness of the implementation an extensive Monte-Carlo test is performed. This publication includes the full specification of the DES algorithm, a complete listing of the DES test set, and a detailed description of the interface to the testbed.

17. KEY WORDS (six to twelve entries; alphabetical order; capitalize only the first letter of the first key word unless a proper name; separated by semicolons)

Communications security; computer security; cryptography; encryption standard; interface requirements; Monte-Carlo testing; testbed; test cases; validating correctness.

18. AVAILABILITY Q Unlimited

For Official Distribution. Do Not Release to NTIS

X Order From Sup. of Doc., U.S. Government Priotipe Qffice Washington, D.C. 20402, SD Cat. No.

[ Order From Nacional Technical Information Service (NTIS) Springfield, Virginia 22151

\begin{tabular}{|l|c|}
\hline $\begin{array}{l}\text { 19. SECURITY CLASS } \\
\text { (THIS REPURT) }\end{array}$ & 21. NO. OF PAGES \\
UNCL ASSIFIED & 46 \\
\hline $\begin{array}{l}\text { 20. SECURITY CLASS } \\
\text { (THIS PAGE) }\end{array}$ & $\begin{array}{c}\text { 22. Price } \\
\text { Price } \$ 2.25\end{array}$ \\
\hline
\end{tabular}





\section{ANNOUNCEMENT OF NEW PUBLICATIONS ON COMPUTER SCIENCE \& TECHNOLOGY}

Superintendent of Documents, Government Printing Office, Washington, D. C. 20402

Dear Sir:

Please add my name to the announcement list of new publications to be issued in the series: National Bureau of Standards Special Publication 500-.

Name

Company

Address

City State Zip Code

(Notification key $\mathrm{N}-503$ ) 



\section{PERIODICALS}

JOURNAL OF RESEARCH-The Journal of Research of the National Bureau of Standards reports NBS research and development in those disciplines of the physical and engineering sciences in which the Bureau is active. These include physics, chemistry, engineering, mathematics, and computer sciences. Papers cover a broad range of subjects, with major emphasis on measurement methodology and the basic technology underlying standardization. Also included from time to time are survey articles on topics closely related to the Bureau's technical and scientific programs. As a special service to subscribers each issue contains complete citations to all recent Bureau publications in both NBS and nonNBS media. Issued six times a year. Annual subscription: domestic \$1 3: lorcign $\$ 16.25$. Single copy, \$3 domestic: \$3.75 forcign.

NOTE: The Journal was formerly published in two sections: Section A "Physics and Chemistry" and Section B "Mathematical Sciences."

DIMENSIONS/NBS-This monthly magazine is published to inform scientists, engineers, business and industry leaders, teachers, students, and consumers of the latest advances in science and technology, with primary emphasis on work at NBS. The magazine highlights and reviews such issues as energy research, fire protection, building technology, metric conversion, pollution abatement, health and safety, and consumer product performance. In addition, it reports the results of Bureau programs in measurement standards and techniques, properties of matter and materials, engineering standards and services, instrumentation, and automatic data processing. Annual subscription: domestic \$11; foreign \$13.75.

\section{NONPERIODICALS}

Monographs-Major contributions to the technical literature on various subjects related to the Bureau's scientific and technical activities.

Handbooks-Recommended codes of engineering and industrial practice (including safety codes) developed in cosperation with interested industries, professional organizations, and regulatory bodies.

Special Publications-Include proceedings of conferences sponsored by NBS, NBS annual reports, and other special publications appropriate to this grouping such as wall charts, pocket cards, and bibliographies

Applied Mathematics Series-Mathematical tables, manuals, and studies of special interest to physicists, engineers, chemists, biologists, mathematicians, computer programmers, and others engaged in scientific and technical work.

National Standard Reference Data Series-Provides quantitative data on the physical and chemical properties of materials, compiled from the world's literature and critically evaluated. Developed under a worldwide program coordinated by NBS under the authority of the National Standard Data Act (Public Law 90-396).
NOTE: The principal publication outlet for the forcgoing data is the Journal of Physical and Chemical Reference Data (JPCRD) published quarterly for NBS by the American Chemical Socicty (ACS) and the American Institute of Physics (AIP). Subscriptions, reprints, and supplements available from ACS, 1155 Sixteenth St. NW, Washington, DC 20056.

Building Science Series-Disseminates technical information develored at the Bureau on building materials, components, systems, and whole structures. The series presents research results, test methods, and performance criteria related to the structural and environmental functions and the durability and safety characteristics of building elements and systems.

Technical Notes-Studies or reports which are complete in themselves but restrictive in their treatment of a subject. A nalogous to monographs but not so comprehensive in scope or definitive in treatment of the subject area. Often serve as a vehicle for final reports of work performed at NBS under the sponsorship of other government agencies.

Voluntary Product Standards-Developed under procedures published by the Department of Commerce in Part 10, Title 15, of the Code of Federal Regulations. The standards establish nationally recognized requirements for products, and provide all concerned interests with a basis for common understanding of the characteristics of the products. NBS administers this program as a supplement to the activities of the private sector standardizing organizations.

Consumer Information Series-Practical information, based on NBS research and experience, covering areas of interest to the consumer. Easily understandable language and illustrations provide useful background knowledge for shopping in today's technological marketplace.

Order the above NBS publications from: Superintendent of Documents, Government Printing Office, Washington. DC 20402.

Order the following NBS publications-FIPS and NBSIR's-from the National Technical Information Services, Springfield, VA 22161.

Federal Information Processing Standards Publications (FIPS PUB)-Publications in this series collectively constitute the Federal Information Processing Standards Register. The Register serves as the official source of information in the Federal Government regarding standards issued by NBS pursuant to the Federal Property and Administrative Services Act of 1949 as amended, Public Law 89-306 (79 Stat. 1127), and as implemented by Executive Order 11717 (38 FR 12315, dated May 11, 1973) and Part 6 of Title 15 CFR (Code of Federal Regulations).

NBS Interagency Reports (NBSIR) - A special series of interim or final reports on work performed by NBS for outside sponsors (both government and non-government). In general, initial distribution is handled by the sponsor; public distribution is by the National Technical Information Services, Springfield, VA 22161, in paper copy or microfiche form.

\section{BIBLIOGRAPHIC SUBSCRIPTION SERVICES}

The following current-awareness and literature-survey bibliographies are issued periodically by the Bureau:

Cryogenic Data Center Current Awareness Service. A literature survey issued biweekly. Annual subscription: domestic $\$ 35$; foreign $\$ 45$.

Liquefied Natural Gas. A literature survey issued quarterly. Annual subscription: $\$ 30$.
Superconducting Devices and Materials. A literature survey issued quarterly. Annual subscription: $\$ 45$. Please send subscription orders and remittances for the preceding bibliographic services to the National Bureau of Standards, Cryogenic Data Center (736) Boulder, CO 80303. 
National Bureau of Standards Washington, O.C. 20234

POSTAGE ANO FEES PAID

OFFICIAL BUSINESS U.S. OEPARTMENT OF COMMERCE COM-215

Penalty for Private Use. $\$ 300$

SPECIAL FOURTH-CLASS RATE BOOK

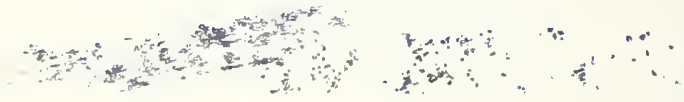

